\title{
EXChange RATe AND Inflation Risk PRemiUMS IN THE EMU ${ }^{\dagger}$
}

\author{
M. BEGOÑA FONT ${ }^{\star}$ AND AlFredo JUAN GRAU* \\ ${ }^{\star}$ Dept. of Mathematics for Economics and Business \\ ${ }^{*}$ Dept. of Corporative Finance \\ University of Valencia (SPAIN)
}

\begin{abstract}
This paper tests the effects of exchange rate and inflation risk factors on asset pricing in the European Union (EU) stock markets. This investigation is motivated by the results of Vassalou (2000) [Journal of International Money and Finance, 19, 433-70] showing that both exchange rate and foreign inflation are generally priced in equity returns, and the opportunity to evaluate the causality between these sources of risk after the elimination of the EU currency risks because of the adoption of the single currency. Our results show that both exchange rate and inflation risks are significantly priced in the pre- and post-euro periods. Moreover, the size of exchange rate and inflation risk premiums are economically significant in the pre- and post-euro periods. Futhermore, the UK and excluding-UK inflation risk premiums explain in part our evidences about a large EUR/GBP exchange rate risk premia and the existence of an economically significant domestic -non-diversifiable risk after the Euro adoption. Hence overlooking inflation risk factors can produce an under/overestimation of the currency premiums and a miscalculation of the degree of integration of stock markets.
\end{abstract}

JEL CLASSIFICATION CODES: F36, G12, G15.

KEY WORDS: International asset pricing; exchange rate risk; inflation risk; time-varying beta risks and risk premiums; European Union.

\footnotetext{
$\dagger^{\dagger}$ Acknowledgements will be included after review.
} 


\section{INTRODUCTION}

On 1 January 1999, eleven countries of the European Union (Austria, Belgium, Finland, France, Germany, Ireland, Italy, Luxembourg, Netherlands, Portugal and Spain) replaced their currencies by the Euro which became the shared currency for every transaction in the monetary and stock markets. On 1 January 2001 Greece joined them and on 1 January 2002 these twelve countries put eurodenominated notes and coins into circulation. These measures made visible an intensive integration process of European countries to achieve the Economic and Monetary Union (EMU) and thus the financial integration of their stock markets.

The benefits of international diversification via financial integration have been known for decades, but to manage the risk of international portfolios, investors need to know the factors that explain the within-country and cross-country differences in the returns of equities. The purpose of this paper is to investigate these factors in the context of the EMU; hence we investigate the effects of the EU plus UK market, exchange rate and foreign inflation risk factors on an international asset pricing model, distinguishing between the pre- and post-euro periods and using individual monthly security data from the 12 UME members and the UK from January 1993 to December 2004. The consideration of exchange rate and inflation risk factors is motivated by four international asset pricing models: the international CAPM and namely the Grauer, Litzenberger and Stehle (1976) model, the Solnik (1974) model (as revised by Sercu (1980)), and the Adler and Dumas (1983) model, and especially by the empirical evidence presented by Vassalou (2000) about significant exchange rate and foreign inflation risk premiums in the cross-section of equity returns using individual security data from 10 developed markets (Australia, Canada, France, Germany, Italy, Japan, the Netherlands, Switzerland, the UK, and USA) for the period from January 1973 to December 1990. Therefore, to test for the relative importance of exchange rate and inflation risks in the pricing of equities, we estimate the specification of the Adler and Dumas (1983) model proposed by Vassalou (2000) conditionally, using the two-stage procedure proposed by Fama and MacBeth (1973) for getting the series of conditional betas and risk premiums associated to each factor of risk. This procedure allows us to separate and mesure the premiums due to exchange rate and inflation risks in the pricing of the EU and the UK equities in the pre- and post-euro period, and to extend the Vassalou's (2000) paper in several ways. First, the model is estimated conditionally; second, the economic impact of market, currency and inflation is measured; third, the dynamics of market, currency and inflation risk premiums are jointly analysed using the vector autoregressive (VAR) methodology; and fourth this paper analyses how each risk premia is affected by the effects of the Euro adoption and characteristics of portfolio on the dynamics of its beta and risk premiums components. Finally, the results are re-analysed, in the light of the level of financial integration achieved by EMU members, estimating a nationalized version (see e.g., Stehle (1977)) of the previous tested international asset-pricing model.

Despite their important implications for the pricing and hedging risks, the effects of inflation risks and their links with exchange rate risks in asset pricing have been overlooked in previous studies analyzing the effects of EMU on EU stock markets. Further, there is still no sufficient evidence about the contribution of foreign inflation and exchange rate risks to explain within-country cross-sectional differences in returns. Revising briefly previous literature, international market and exchange risk premiums and their relevance in the EMU are analysed by Carrieri (2001) (monthly returns on stock indices of France, Germany, Italy and UK, for the period from March 1974 to August 1995) and De Santis, Gerard and Hillion (2003) (monthly returns on stock indices for 10 countries -Austria, Belgium, France, Germany, Italy, Japan, the Netherlands, Spain, UK and USA, from January 1974 to December 1997) estimating and discussing the Solnik (1974) model. Finally, Hardouvelis, 
Malliaropulos and Priestley (2006) (weekly returns on stock indices for the $11 \mathrm{EU}$ counties -Greece is excluded for the period February 7, 1992 to June 26, 1998) measured the relative influence of EU market and exchange rate risks factors over each country market risk factor on returns. None of these papers extends its analysis to the post-euro period.

Our results reveal that exchange rate risk premiums and inflation risk premiums are significantly priced in the pre- and post-euro periods and they suggest the higher relative importance of the inflation risk premiums shocks in the exchange rate risk premium forecasts after the adoption of the single currency. Futhermore, the size of EUR/GBP exchange rate and inflation risk premia are economically significant after the Euro adoption and the former is explained by the large positive impact of a large negative UK inflation premium on future values of the common exchange rate premium combined with a small positive price of EUR/GBP exchange rate risk. These findings remain when a domestic risk factor is considered to measure the lack of financial integration in EMU, and the effect of inflation risks also explain in part the remaining significantly domestic risk premia of some sector and size-BM portfolios after the Euro adoption.

The rest of the paper is organized as follows. Section 2 outlines the international asset pricing model which underpins our tests in its standard and nationalized versions and lays out our econometric approach. Section 3 describes the data and the portfolio construction. Section 4 discusses the empirical results. Section 5 re-examines the previous results considering the level of integration achieved by the EU plus the UK stock markets and Section 6 concludes the paper with a summary.

\section{A MODEL OF INTERNATIONAL ASSET PRICING AND METHODOLOGY}

Over the last forty years, stock markets have become more open to foreign investors and a vast literature looks at the effects of this liberalization on asset prices (see for instance the review of Solnik (1977), Stulz (1995) and Karolyi and Stulz (2003)). The purpose of this Section is to describe the main international asset pricing in its standard and nationalized versions and outline our econometric approach and methodology.

\subsection{A MODEL OF INTERNATIONAL ASSET PRICING AND ITS NATIONALIZED VERSION}

The models of international asset pricing, deriving equilibrium pricing relationships and risk-return trade-off from individual portfolio maximization in an international setting, face two main assumptions about the level of financial integration of stock markets: identical vs. different consumption opportunity sets and identical vs. different investment opportunity sets across countries. The consumption opportunity sets differ across countries when the relative prices of goods depend on where they are located and/or there are differences between the existing goods in each country and/or there are differences in tastes that determine a different basket of goods. Whereas investmentopportunity sets differs across countries when the barriers to the investment drives a wedge between returns on assets for residents and for nonresidents.

In a world with identical investment-opportunity sets but different consumption-opportunity sets across countries, Adler and Dumas (1983) provide a general asset pricing model where the expected excess returns of risky assets are linear functions of their betas with respect to the international market portfolio and with inflation (or, under some assumptions, exchange rate) risk factors. The Adler and Dumas (AD) model assumes that investors of $\mathrm{K}+1$ countries have potentially different consumption preferences and hence they measure inflation by different price indexes. Assume there are $\mathrm{N}$ risky assets of which the first $\mathrm{n}=\mathrm{N}-\mathrm{K}$ are stock securities and the remainder $\mathrm{K}$ are nominal bank deposits denominated in the $\mathrm{K}$ currencies, which are nominally risky when they are expressed in terms of the reference currency. The $\mathrm{K}+1^{\text {st }}$ security is a bank deposit denominated in units of the reference country 
and it is nominally riskless. In equilibrium, an investor of country $\mathrm{k}$ holds a combination of the world market portfolio and an inflation hedge portfolio which hedges against the inflation of his country, and the expected excess return of asset $j$ (over the risk-free interest rate denominated in units of the reference country) obeys the following equation:

$$
\mathrm{E}\left(\mathrm{r}_{\mathrm{j}}\right)=\gamma_{0}+\gamma^{\mathrm{m}} \beta_{\mathrm{j}}^{\mathrm{m}}+\sum_{\mathrm{k}=1}^{\mathrm{K}+1} \gamma_{\mathrm{k}}^{\pi} \beta_{\mathrm{jk}}^{\pi}
$$

Where $E\left(r_{j}\right)$ is the expected excess of asset $j ; \gamma^{m}$ is the expected excess return of the world market portfolio (market risk premium) ; $\beta_{\mathrm{j}}^{\mathrm{m}}$ is the regression beta of asset $\mathrm{j}$ with the excess return on the world market portfolio; $\gamma_{\mathrm{k}}^{\pi}$ is the expected excess return of a portfolio which is as highly correlated as possible with the inflation rate in country $\mathrm{k}$ (inflation risk premium of country $\mathrm{k}$ ); and $\beta_{\mathrm{jk}}^{\pi}$ is the regression beta of asset $\mathrm{j}$ with the inflation of country $\mathrm{k}$. The $\mathrm{AD}$ model implies $\gamma_{0}=0$, $\gamma^{\mathrm{m}}=\mathrm{E}\left(\mathrm{r}^{\mathrm{m}}\right)-\gamma_{0}$ and $\gamma_{\mathrm{k}}^{\pi}=\mathrm{E}\left(\mathrm{i}_{\mathrm{k}}\right)-\gamma_{0}$ where $\mathrm{i}_{\mathrm{k}}$ denotes the inflation rate of country $\mathrm{k}$. But the Eq. [1], including $\gamma_{0}$, also supports a Black (1972)-type version of the AD model where the return of the zero-beta portfolio should be equal to the risk-free rate plus $\gamma_{0}$.

The AD model collapses into the model presented by Solnik (1974) and revised by Sercu (1980) (the S-S model as we will call it) on the assumption that there is a product or asset for each country whose price is constant in the currency of that country; there are as many products or assets as there are countries and investors consume only the product or asset that has zero inflation in their country or whose inflation is nonstochastic. In this case, an investor of country $\mathrm{k}$ holds a combination of the world market portfolio and the bond of his country, and the expected excess returns of risky assets are linear functions of their betas with respect to the world market and exchange rate risk factors. This S-S model is the international asset-pricing model tested in the papers of Carrieri (2001) and De Santis, Gerard and Hillion (2003) for measuring the relevance of currency risk in the context of the EMU. Similarly, the AD model collapses into the model derived by Grauer, Litzenberger and Stehle (1976) (namely it GLS model) when we assume that inflation is stochastic but the consumption opportunity sets across countries are identical, and into the international capital asset pricing model (ICAPM) when we assume identical consumption-opportunity sets across countries and zero or nonstochastic inflation or when investors have logarithmic utility (see e.g., Adler and Dumas (1983) and Stulz (1995)). In the former, the expected excess return of risky assets are linear functions of their betas with respect to the world market portfolio and the reference-country inflation risk factor, and in the latter they are linear functions of their beta with respect to the world market portfolio.

The AD model allows us to test for the pricing of inflation risk, but not the relative importance of exchange rate and inflation risks because, in the model, the former is embedded in the latter. Therefore, Vassalou (2000) proposes a 'nested' version of AD, S-S and GLS models into one specification, overparameterizing the $\mathrm{AD}$ model (we call it $\mathrm{AD}-\mathrm{V}$ model) in the following manner:

$$
\mathrm{E}\left(\mathrm{r}_{\mathrm{j}}\right)=\gamma_{0}+\gamma^{\mathrm{m}} \beta_{\mathrm{j}}^{\mathrm{m}}+\sum_{\mathrm{k}=1}^{\mathrm{K}+1} \gamma_{\mathrm{k}}^{\pi} \beta_{\mathrm{jk}}^{\pi}+\sum_{\mathrm{k}=1}^{\mathrm{K}} \gamma_{\mathrm{k}}^{\mathrm{f}} \beta_{\mathrm{jk}}^{\mathrm{f}}
$$

Where the inflation terms are stated in the reference country $\mathrm{K}+1 ; \gamma_{\mathrm{k}}^{\mathrm{f}}$ is the expected excess return (exchange risk premium of country $\mathrm{k}$ ) of a portfolio which is as highly correlated as possible with the return of bond of country $\mathrm{k}$ expressed in the reference currency (i.e. the exchange rate between currency $k$ and the reference currency $\mathrm{K}+1$ ); and $\beta_{\mathrm{jk}}^{\mathrm{f}}$ is the regression beta of asset $\mathrm{j}$ with the exchange rate between currencies $\mathrm{k}$ and $\mathrm{K}+1$. 
An alternative approach to pricing international assets is the proposed by Fama and French (1998) who argue that the global market risk is unable to capture the cross-sectional return spreads among portfolios soted by size and book-to-market ratio in the global market. However, Zhang (2006) shows that the Fama-French factors are redundant in the presence of business cycle variables. In this paper, we will assume the international models hold in a conditional form, and therefore we will estimate and test the AD-V model in the context of the EMU with the UK as the reference country and substituting the world market for the EU plus the UK market portfolio in the valuation of the market factor risk. Although we cannot strictly identify the AD-V model with the AD model because the inflation terms are stated in the reference currency rather than in the local currency, the AD-V model has some interesting features. Testing this model we accept the AD model if $\gamma_{\mathrm{k}}^{\mathrm{f}}=0, \forall \mathrm{k}$, the S-S model if $\gamma_{\mathrm{k}}^{\pi}=0, \forall \mathrm{k}$, the GLS model ${ }^{1}$ if $\gamma_{\mathrm{k}}^{\mathrm{f}}=0, \forall \mathrm{k}$ and $\gamma_{\mathrm{k}}^{\pi}=0, \forall \mathrm{k} \neq \mathrm{K}+1$, and the ICAPM if $\gamma_{\mathrm{k}}^{\mathrm{f}}=0$ and $\gamma_{\mathrm{k}}^{\pi}=0, \forall \mathrm{k}$. Moreover, we can measure the relative importance of exchange rate and inflation risks in the pricing of equities, the additional contribution of inflation risks over the market and exchange rate risks to the expected excess of risky assets, and the causal relationship between these sources of risks after the adoption of the single currency.

The hypothesis about a common risk premium across countries and consequently stock markets perfectly integrated is assumed implicitly in the ICAPM and GLS formulations because for these models the purchasing power parity holds, and in the S-S model because the risk associated with the currency can be perfectly hedged ${ }^{2}$. Moreover, this hypothesis is also accepted (explicitly) in the AD model and AD-V models when these models are estimated assuming the same value of risk premium across countries. Thus, we can measure the impact of international market, inflation and exchange rate risks on pricing but we cannot test if the market is also pricing domestic risks. To evaluate if the market is integrated or not and measure the effect of this possible lack of integration in the pricing of equities, following the methodology proposed by Stehle (1977), we will also estimate and test the "nationalized" AD-V model stated as follows:

$$
\mathrm{E}\left(\mathrm{r}_{\mathrm{j}}\right)=\gamma_{0}+\gamma^{\mathrm{m}} \beta_{\mathrm{j}}^{\mathrm{m}}+\gamma^{\mathrm{d}} \beta_{\mathrm{jk}}^{\mathrm{d}}+\sum_{\mathrm{k}=1}^{\mathrm{K}+1} \gamma_{\mathrm{k}}^{\pi} \beta_{\mathrm{jk}}^{\pi}+\sum_{\mathrm{k}=1}^{\mathrm{K}} \gamma_{\mathrm{k}}^{\mathrm{f}} \beta_{\mathrm{jk}}^{\mathrm{f}}
$$

Where $\gamma^{\mathrm{m}}$ is the expected excess return of the EU plus the UK market portfolio; $\beta_{j}^{\mathrm{m}}$ is the regression beta of asset $j$ with the excess return on the EU plus the UK market portfolio; $\gamma^{d}$ is the expected return of the orthogonal domestic factor (domestic risk premium); and $\beta_{\mathrm{jk}}^{\mathrm{d}}$ is the regression beta of asset $j$ with the orthogonal domestic factor; and this orthogonal domestic factor is the equally weighted index of the residuals obtained from the projection of the excess returns of the domestic market portfolio of country $\mathrm{k}\left(\mathrm{r}^{\mathrm{k}}\right)$ on the excess returns of the EU plus the UK market portfolio $\left(\mathrm{r}^{\mathrm{m}}\right)$ through the regression: $\mathrm{r}^{\mathrm{k}}=\alpha_{\mathrm{k}}^{\mathrm{dm}}+\beta_{\mathrm{k}}^{\mathrm{dm}} \mathrm{r}^{\mathrm{m}}+\mathrm{e}_{\mathrm{k}}, \mathrm{k}=1, \ldots, \mathrm{K}+1$. Therefore $\gamma^{\mathrm{d}}$ can be interpreted as the expected compensation for a risk that is domestically but not internationally diversifiable.

\footnotetext{
1 The GLS model assume one single inflation rate in which, because of PPP holds, all country inflation rates collapsed when they are expresed in terms of the same reference currency, so it does not provide guidance on which inflation rate should be priced. Here we assume that the reference country is the prominent country so their inflation rate is the inflation risk factor of the model.

${ }^{2}$ See the section VII of Adler and Dumas's (1983) paper and specially footnote number 86.
} 


\subsection{ECONOMETRIC APPROACH}

The AD-V model in its standard (Eq. [2]) and domestic (Eq. [3]) versions is based on the assumption that first and second moments are constant. Hence, the marginal and conditional moments are identical and the investment opportunity sets are identical across countries. This hypothesis is not appropriate for analyzing the effects of exchange rate and inflation risks on equity returns in the process of the UME, a dynamic process indeed subject to political and economic agreements among EU members and the effect of the economic cycle itself. Therefore, a conditional analysis of the model is more likely to provide useful insights into the issues that we want to address.

The assumption of a stochastic investment opportunity set can be introduced easily in the model assuming that the previous theoretical models are satisfied in a conditional form (this is, that their first and second moments are the result of the available information) and estimating the models conditionally using the scaling procedure ${ }^{3}$ proposed by Cochrane (1996). In this paper two instrumentals variables have been chosen for their capacity to predict the evolution of economic cycle in the long-medium and short term ${ }^{4}$ : the dividend yield on the European equity index (div) and the UK term spread (term) defined as the difference between four and one year zero coupon UK Treasury bonds.

To make the model empirically tractable, we need to define how to calculate "a portfolio which is as highly correlated as possible with the inflation rate in country k" and "a portfolio which is as highly correlated as possible with the return of bond of country k expressed in the reference currency" in the Eq. 1 to 3 . In reference to the first question and in order of preserving the possibility of testing between the AD and GLS models, diminishing the multicollinearity problems and reducing the dimensionality of exchange rates, we implement the Vasalou's (2000) solution. Hence, we consider two indexes: the UK inflation factor $\left(\mathrm{r}^{\mathrm{i}}\right)$, which measures the UK inflation uncertainty, and the excluding-UK inflation $\left(\mathrm{r}^{\mathrm{D}}\right)$, which measures the inflation uncertainty that is unrelated to $\mathrm{UK}$ inflation. To calculate these factors: first, we filter the twelve inflation rate series (expressed in British pounds) using an $\operatorname{ARIMA}(0,1,1)$ model $^{5}$; second, we make the UK inflation factor equal to the innovations of the UK inflation rate series; third, we construct the GDP weigthed index ${ }^{6}$ of EMU inflation expressed in British pounds from the innovations of the inflation rate series of all EU countries; and finally, since we are interested in the pricing of the EU plus the UK which is residual to the UK inflation risk, we render the two series orthogonal to each other projecting the GDP weighted index of EMU inflation on the UK inflation factor and taking the excluding-UK inflation as the residuals of this projection.

The question related to the currency risk factor has been previously solved using an index of changes in exchange rates (see, e.g., Jorion (1991)), or changes in a small number of exchange rates (see, e.g., Dumas and Solnik (1995), Carrieri (2001)), or combining the information of changes in exchange rates in two indexes: the common component index, which measures movements which tend

\footnotetext{
${ }^{3}$ Whereas in the scaling procedure the dynamics are introduced in the discount factors of the equation of valuation of the asset pricing model, in the alternative solution proposed by Dumas and Solnik (1995) the dynamics are introduced on the risk premiums directly.

${ }^{4}$ See e.g., Fama and French $(1988,89)$, Cochrane $(1996)$ and Ferson and Harvey $(1991,99)$.

${ }^{5}$ The inflation series are filtered to avoid the estimation problems due to unit roots, so the inflation factors should be understood as denoting innovations rather than levels of inflation rates. The ARIMA $(0,1,1)$ model is widely used for inflation forecasting. For evidence on the comparative performance of the model, see Fama and Gibbons (1984).

${ }^{6}$ The AD model motivates the weighting scheme employed. See footnote 6 of Vassalou's (2000) paper.
} 
to be common across all exchange rates, and the residual exchange rate index, which aggregate the fluctuations which are specific to the individual exchange rate. The latest is the solution applied in Vassalou's (2000) paper and this study because it diminishes the multicollinearity problems, reduces the dimensionality of exchange rates and results in the inclusion of more information about changes in currency than the single index method (see Vassalou (2000)) simultaneously. Adapting the Vassalou's (2000) solution to the EU plus the UK stock markets and sample period, we divide our sample into two groups: the pre-euro period (from January 1993 to December 1998) with eleven exchange rates ${ }^{7}$ and the post-euro one ${ }^{8}$ (from January 1999 to December 2004) with only one exchange rate (EUR/GBP). For the observations of the pre-euro period we project the changes in exchange rates ${ }^{9}$ in each of the $\mathrm{K}$ countries on the remaining $\mathrm{K}-1$ exchange rates through the following regression for $\mathrm{k}=1,2, \ldots, 11$ :

$$
\mathrm{r}_{\mathrm{k}}^{\mathrm{f}}=\delta_{0 \mathrm{k}}+\sum_{\mathrm{j} \neq \mathrm{k}} \delta_{\mathrm{j} 1} \mathrm{r}_{\mathrm{j}}^{\mathrm{f}}+\mathrm{e}_{\mathrm{k}}
$$

Where $r_{k}^{\mathrm{f}}$ is the logarithmic change in exchange rate expressed in British pounds between currency $\mathrm{k}$ and British currency. Thus, the residual $e_{k}$ represent the component of $r_{k}^{f}$ that is not explained by the changes in the remaining exchange rates, i.e. their residual component; $t_{k}=r_{k}^{f}-\delta_{0 k}-e_{k}$ is the common (or systematic) component of the $\mathrm{K}$ exchange rates; and $\mathrm{n}_{\mathrm{k}}=\mathrm{t}_{\mathrm{k}}-\overline{\mathrm{t}}$ is the deviation of the common component of the $\mathrm{K}$ exchange rates from its mean. Up to this point, there is no loss of information and each exchange rate is simply a linear combination of its common and idiosyncratic component. We then construct two equally weighted indexes corresponding to the two sets of residuals for the pre-euro period: the common exchange rate factor defined by $r^{\lambda}=1 / 11 \sum_{k=1}^{11} n_{k}$ that describes the average common component shared by changes in the same exchange rates, and the residual exchange factor defined by $\mathrm{r}^{\mathrm{e}}=1 / 11 \sum_{\mathrm{k}=1}^{11} \mathrm{e}_{\mathrm{k}}$ which is the average residual component of changes in all eleven exchange rates. For the rest of the sample (the post-euro period) we simply define these factors as $r^{\lambda}=r_{\text {euro }}^{\mathrm{f}}$ and $r^{\mathrm{e}}=0$ respectively, where $r_{\text {euro }}^{\mathrm{f}}$.denotes the change in exchange rate expressed in British pounds between euro and British pounds.

Based on the data transformations and the conditional approach followed in this paper the AD-V model in its marginal version becomes:

$$
\begin{aligned}
& \mathrm{E}\left(\mathrm{r}_{\mathrm{j}}\right)=\gamma_{0}+\gamma^{\mathrm{m}} \beta_{\mathrm{j}}^{\mathrm{m}}+\gamma^{\mathrm{i}} \beta_{\mathrm{j}}^{\mathrm{i}}+\gamma^{\mathrm{D}} \beta_{\mathrm{j}}^{\mathrm{D}}+\gamma^{\lambda} \beta_{\mathrm{j}}^{\lambda}+\gamma^{\mathrm{e}} \beta_{\mathrm{j}}^{\mathrm{e}}+\gamma^{\mathrm{m} \cdot \mathrm{div}} \beta_{\mathrm{j}}^{\mathrm{m} \cdot \mathrm{div}}+\gamma^{\mathrm{i} \cdot \mathrm{div}} \beta_{\mathrm{j}}^{\mathrm{i} \cdot \mathrm{div}}+\gamma^{\mathrm{D} \cdot \mathrm{div}} \beta_{\mathrm{j}}^{\mathrm{D} \cdot \mathrm{div}} \\
& +\gamma^{\lambda \text {-div }} \beta_{\mathrm{j}}^{\lambda \text {-div }}+\gamma^{\text {e.div }} \beta_{\mathrm{j}}^{\text {e.div }}+\gamma^{\mathrm{m} \cdot \text { term }} \beta_{\mathrm{j}}^{\mathrm{m} \cdot \text {-term }}+\gamma^{\mathrm{i} \text {-term }} \beta_{\mathrm{j}}^{\text {i.term }}+\gamma^{\text {D.term }} \beta_{\mathrm{j}}^{\text {D.term }} \\
& +\gamma^{\lambda \text { term }} \beta_{\mathrm{j}}^{\lambda \text { term }}+\gamma^{\text {e.term }} \beta_{\mathrm{j}}^{\text {e.term }}+\gamma^{\text {div }} \beta_{\mathrm{j}}^{\text {div }}+\gamma^{\text {term }} \beta_{j}^{\text {term }}
\end{aligned}
$$

\footnotetext{
${ }^{7}$ Our database does not distinguish between Belgium and Luxemburg stock markets.

${ }^{8}$ Although strictly speaking Greece switched to the Euro on 1 January 2001 and we have to distinguish two "post-euro adoption" periods for this country (from January 1999 to December 2000 and from January 2001 to December 2004). Both the stability of the drachma in the period from January 1999 to December 2000 and the high correlation of the factors considering two subperiods or the whole period: 0.99371 and 0.96889 for the common and residual exchange rate risk factors respectively make this distinction worthless.

${ }^{9}$ Under the assumption that exchange rates follow a random walk, changes in the exchange rates represent also innovations.
} 
Where $E\left(r_{j}\right)$ is the expected excess of asset $j$ expressed in British pounds; $\gamma^{F}, F=m, i, D, \lambda$, e are the risk premiums associate with the EU plus UK market, UK inflation, excluding-UK inflation, common exchange rate and residual exchange rate risk factors respectively; $\beta_{\mathrm{j}}^{\mathrm{F}}, \mathrm{F}=\mathrm{m}, \mathrm{i}, \mathrm{D}, \lambda$, e are the beta risks of asset $\mathrm{j}$ with the EU plus UK market, UK inflation, excluding-UK inflation, common exchange rate and residual exchange rate risk factors respectively; $\gamma^{\mathrm{F} \cdot \mathrm{I}}$ and $\beta_{\mathrm{j}}^{\mathrm{F} \cdot \mathrm{I}}, \mathrm{F}=\mathrm{m}, \mathrm{i}, \mathrm{D}, \lambda, \mathrm{e}, \mathrm{I}=\mathrm{div}$, term have the same interpretation but referred to the price of the cross effects of each risk factors with the economic cycle (predicted by the two instrumental variables lagged one-month); and $\gamma^{\mathrm{I}}$ and $\beta_{\mathrm{j}}^{\mathrm{I}} \mathrm{I}=\mathrm{div}$, term are the risk premiums and beta risks associated with the economic cycle.

Similarly, the "nationalized" AD-V in its marginal version can be writen as:

$$
\begin{aligned}
& \mathrm{E}\left(\mathrm{r}_{\mathrm{j}}\right)=\gamma_{0}+\gamma^{\mathrm{m}} \beta_{\mathrm{j}}^{\mathrm{m}}+\gamma^{\mathrm{d}} \beta_{\mathrm{j}}^{\mathrm{d}}+\gamma^{\mathrm{i}} \beta_{\mathrm{j}}^{\mathrm{i}}+\gamma^{\mathrm{D}} \beta_{\mathrm{j}}^{\mathrm{D}}+\gamma^{\lambda} \beta_{\mathrm{j}}^{\lambda}+\gamma^{\mathrm{e}} \beta_{\mathrm{j}}^{\mathrm{e}}+\gamma^{\mathrm{m} \cdot \mathrm{div}} \beta_{\mathrm{j}}^{\mathrm{m} \cdot \mathrm{div}}+\gamma^{\mathrm{d} \cdot \mathrm{div}} \beta_{\mathrm{j}}^{\mathrm{d} \cdot \mathrm{div}} \\
& +\gamma^{\text {i.div }} \beta_{j}^{\text {i.div }}+\gamma^{\text {D.div }} \beta_{j}^{\text {D.div }}+\gamma^{\lambda \cdot \text { div }} \beta_{j}^{\lambda \cdot d i v}+\gamma^{\text {e.div }} \beta_{j}^{\text {e.div }}+\gamma^{\text {m.term }} \beta_{j}^{\text {m.term }}+\gamma^{\text {d.term }} \beta_{j}^{\text {d.term }} \\
& +\gamma^{\text {i.term }} \beta_{j}^{\text {i.term }}+\gamma^{\text {D.term }} \beta_{j}^{\text {D.term }}+\gamma^{\lambda \text {.term }} \beta_{j}^{\lambda \text {.term }}+\gamma^{\text {e.term }} \beta_{j}^{\text {e.term }}+\gamma^{\text {div }} \beta_{j}^{\text {div }}+\gamma^{\text {term }} \beta_{j}^{\text {term }}
\end{aligned}
$$

To estimate these models (the second one for robustness purposes) we use monthly total returns and a version of the two-stage procedure proposed by Fama and MacBeth (1973). This classic methodology offers some appealing features for this study. Particularly, this method generates the series of conditional betas and risk premiums associated to each factor of risk ${ }^{10}$ and it allows the analysis of the reward for each source of risk as the result of time-varying institutional and economic conditions.

The AD-V model in its standard and nationalized versions is estimated using the following twostage procedure ${ }^{11}$. In the first step we obtain the series of conditional betas associated to each factor regressing the excess returns on each risk factor ${ }^{12}$ for the time series of months $t-48$ to $t-1$ using the ordinary least squares (OLS) method. The slope coefficients in the time-series regressions provide the conditional beta given the information available at month $\mathrm{t}-1$. The second step is to estimate the corresponding cross-sectional regression ${ }^{13}$ for each month of the excess returns on the estimated betas. These cross-sectional regressions, which provide the conditional series of risk premiums, are estimated using the seemingly unrelated regression (SUR) method for the previous 48 monthly observations iterating on the weighting matrix and coefficient vector simultaneously. Finally, the risk premiums are jointly estimated using SUR from the series of conditional risk premiums for the pre- and post-euro periods. From the results of this last estimation, we also obtain the T-statistics of each parameter to

\footnotetext{
${ }^{10}$ This was the method used by Ferson and Harvey $(1991,99)$ for getting the series of conditional betas and risk premiums.

${ }^{11}$ An alternative popular method of getting these conditional series is the GARCH methodology (see e.g., De Santis and Gerard (1997)), but this method is not appropriate for this study because it assumes a dynamic structure for the excess of returns and risk premiums that do not adjust with the descriptive statistics of these series (see Section 3.2).

${ }^{12}$ Other possibility is to estimate the betas jointly according to the most general specification with all the risk factors. The advantage is the reduction of the multicollinearity problems, but the disadvantage is the different economic interpretation of these betas.

${ }^{13}$ To implement this method, it is worth noticing that the residual exchange risk factor disappears in January 1999. Therefore, the series of conditional betas associated with the residual exchange risk have observations only for the pre-euro adoption period (from January 1993 to December 1998), the specification of model change and consequently, the series of conditional risk premium are estimated separately for the pre-euro adoption period and the post-euro adoption one (from January 1999 to December 2004).
} 
test if the EU plus UK market, inflation and currency individual risks are significantly priced, and the Wald test statistics to evaluate the joint hypothesis test on the prices, inflation and currency risks.

This statistical analysis will be completed with the estimation of the economic relevance (or premia) associated to each source of risk overall and for the pre- and post-euro periods (see details in Section 4.2) and the statistical analysis of the dynamics of their components. Specifically, we will estimate from the conditional beta and risk premium series of individual factors: the average exposure to the mean series of beta risk associated to market, domestic, inflation and currency risks overall and for the pre- and post-euro, and the average prices of risk premium associated to individual risks from the model AD-V in its two versions overall and for the pre- and post-euro (see econometric details in Section 4.3). And finally, we will analyse jointly the dynamics and the causality relationships of these conditional individual risk premiums estimating a multivariate VAR(1) model (see econometric details in Sections 4.3, 5.2 and 5.3).

\section{DATA, PORTFOLIO CONSTRUCTION AND SUMMARY STATISTICS}

Our study uses monthly total stock returns from twelve countries namely Austria, BelgiumLuxemburg $^{14}$, Finland, France, Germany, Ireland, Italy, the Netherlands, Portugal, Spain (the Euro Zone) and the United Kingdom (our reference country), and it comprises the period from January 1993 to December 2004. These stocks are classified into three sets: the country set which includes twelve portfolios, the sector set with ten portfolios and the size-book set with nine portfolios. In this Section, we provide the description of data and asset sets.

\subsection{DATA}

Our sample runs from January 1993 to December 2004, a period that comprises the most relevant dates of the European integration process from the creation of the Single Market (01/01/93) and European Union (01/10/93) to accession treaties with the East European countries. In the rest, we will distinguish two periods: the pre-euro period (from January 1993 to December 1998) and the post-euro one (from January 1999 to December 2004) for a better understanding of the effects of integration process on asset pricing and empirical results.

All the monthly total stock returns series are extracted from ECOWIN. To obtain these series we download the series of daily prices, dividends and exchange rates, and we calculate the monthly total returns from the monthly prices expressed in British pounds (our reference currency) spreading evenly the dividends after withholding taxes throughout each year. To make the correction for taxes we use the withholding taxes proposed by STOXX in the construction of its indices as follows: Austria 25\%, Belgium-Luxembourg 25\%, Finland 29\%, France 25\%, Germany $21.1 \%$, Greece $0 \%$, Ireland 20\%, Italy $27 \%$, the Netherlands $25 \%$, Portugal $25 \%$, Spain $15 \%$ and the United Kingdom $0 \%$. Our data includes (after filtering to remove those assets without information about dividends) 1726 equity returns: 62 in Austria, 42 in Belgium-Luxembourg, 119 in Finland, 262 in France, 267 in Germany, 23 in Greece , 50 in Ireland, 129 in Italy, 139 in the Netherlands, 18 in Portugal, 53 in Spain and 562 in the United Kingdom samples.

In the rest of the paper, we proxy the EU plus the UK market portfolio with the index Dow Jones STOXX Broad Europe 600 downloaded from STOXX website. All the excess returns are calculated in excess of the 3-month UK spot interest rate (based on GP repo dates) provided by the Bank of England. The series of inflation rates and GDP data are obtained from EUROSTAT.

\footnotetext{
${ }^{14}$ Our database does not distinguish between Belgium and Luxembourg so both stock markets are considered as a single market
} 
The instrumental variables dividend yield and UK term spread are obtained from the series of monthly prices of index Dow Jones STOXX-600 with and without dividend adjustments facilitated by STOXX and the spot 1-year and 4-year zero coupon UK Treasury bond returns from the Bank of England respectively. Finally, the remaining data to compute the size-BM portfolios are also extracted from the files of ECOWIN.

\subsection{PORTFOLIO CONSTRUCTION AND DESCRIPTIVE STATISTICS}

We consider three asset sets: the country, sector and size-BM portfolios. Table 1: Panel A reports the summary statistics of the monthly total returns on the country, sector and size-BM portfolios. The statistics are means, standard deviations, the Jarque-Bera statistics, the Ljung-Box Q-statistics for returns and square returns up to order 6 , and the mean tests for the excess total return series.

The country set of assets consists of the twelve equal weighted country portfolios constructed from the 1726 monthly total stock returns series. Overall, our results (see Table 1: Panel A) are consistent with those in the literature and we reject the hypothesis of normality at any level for all the series with the exception of the Greece returns. The predominant lack of autocorrelation in returns and squared returns reveals that, in our analysis we do not need to correct for the possibility of dynamics in mean and variances. Finally, the total excess returns are not significant and negative for any portfolio, and they are significant at the 5\% level and positive for France, Ireland, Spain and the United Kingdom portfolios.

The main issue of this paper is to investigate the contribution of the EU plus UK market portfolio, exchange rate and inflation risk factors to explain the within-country and cross-country differences in the returns of equities. A study based in a country or index set (like the ones provided by Carrieri (2001), De Santis, Gerard and Hillion (2003) and Hardouvelis, Malliaropulos and Priestley (2006)) cannot explain the within-country cross-sectional differences in returns due to exchange rate or inflation risk factors.

Moreover, it is known that the risk premiums are not the same for every industry or firm (see e.g., Jorion (1991) and Dahlquist and Sallstrom (2002)) and size and book-to-market portfolios display large cross-sectional return spreads (see Fama and French (1998), so the country porfolios do not provide sufficient evidence to measure the economic relevance of these factors on pricing. Therefore, we think it is a useful complement to our study analyzing two additional sets based on sector and size and book-to-market characteristics.

The sector set consist of ten equal weighted sector portfolios constructed by assigning each stock to one of the RBSS economic sectors according to the information facilitated by REUTERS, and the size-BM set consist of nine equal weighted size and book-to-market sorted portfolios. To construct the size-BM portfolios we rank all the stock according to their average of market capitalization at December 31 from 1992 to 2003 and then sort into three categories -(L)ow, (M)edium and (H)igh size. Within each of these three categories, we further sort all assets into three categories -(L)ow, (M)edium and $(\mathrm{H})$ igh book-to-market, based on their average of book-to-market ratio ${ }^{15}$ for the same period. We name the size-BM portfolios with two letters: the first referred to size and the second to book-tomarket ratio classification.

The conclusions (see Table 1: Panel A) are similar to the ones discussed before for the country portfolios. We reject the hypothesis of normality at $5 \%$ level for all the total returns series with the

\footnotetext{
${ }^{15}$ The information used to calculate the numerator of the book-to-market ratio is the stockholders equity of all countries with the exception of Germany. In this case, the data facilitated by EcoWIN is the long-term debt instead.
} 
exception of the Energy and Telecom sectors and the LM size-BM portfolio. The lack of autocorrelation structure in returns and squared returns on sector portfolios contrasts with their presence in returns on size-BM portfolios but, in any case, the GARCH model represents these dynamics accurately. Besides, the total excess returns are not significant and negative for any portfolio, and they are significant at 5\% level and positive for the Cyclical, Financial, Industrial, Non Cyclical and Utilities sectors and the ML, HL and HM size-BM portfolios. Finally, the higher dispersion in average returns of the sector and size-book portfolios than the country portfolios can be seen in Figure 1, where average returns and standard deviations are depicted.

Table 1: Panel B and C reports the summary statistics of the risk factor series and the one-month lagged instrumental variables. The statistics are means, standard deviations, the Jarque-Bera statistics, the Ljung-Box Q-statistics for returns and square returns up to order 6, the mean tests for the risk factor series and the Augmented Dickey-Fuller statistic of unit root for the instrumental variables.

As regards the summary statistics for the risk factors (see Table 1: Panel B), the hypothesis of normality is also rejected at the $5 \%$ level for every factor with the exception of the residual exchange factor and the means are not significant and negative for any risk factor. As regards the instrumental variables (see Table 1: Panel C) our results confirm previous literature (see e.g. Fama and French $(1988,89))$; both series are very persistent and the autocorrelations of dividend yield are higher than the ones of UK term spread ${ }^{16}$ but they show some tendency towards mean reversion. Although we cannot reject at the $10 \%$ level the hypothesis of unit root for both variables for the period in study; we reject this hypothesis at this level for the longest period from January 1990 to December 2004.

\section{EMPIRICAL RESULTS}

Let us turn to the main aim of this paper; this is to investigate the effects of the EU plus UK market, exchange rate and inflation risk factors on explaining the within-country and cross-country differences in the returns of European equities in the process and early years of the EMU. We proceed in three stages. First, we estimate the AD-V model in its econometric approach (see Eq. [5]) for country, sector and size-BM portfolios to provide a joint estimation of the market, currency and inflation risk premiums for the pre- and post-euro periods. Second, having established the significance and timevarying nature of these factors in asset pricing, we proceed to measure explicitly the premium associated with each source of risk (namely it, risk premia). Third, we examine these results looking at the evidence on the structural changes in the prices and exposure to market, currency and inflation risks. Finally, in Section 5 we will re-examine the robustness of all these results considering the level of integration achieved by European stock markets.

\subsection{PRICE OF MARKET, EXCHANGE RATE AND INFLATION RISKS}

Table 2 contains parameter estimates and some specification tests of the AD-V model discussed earlier in the paper (see Eq. [5]) for country, sector and size-BM asset sets. In Panel A, we report the estimated risk premiums and their individual significance, and in Panel B a number of Wald test statistics to evaluate joint hypothesis on the price of market, currency and inflation risk risks.

We start our analysis with the country portfolios. Consistently with the conditional approach followed in this article, we reject at the $1 \%$ level the hypothesis of instrumental risk premiums equal to zero in the pre- and post-euro periods. Besides, we also reject at the $1 \%$ level the joint hypothesis of all risk premiums equal to zero for both periods. The (individual) price of market risk is significant (at $1 \%$ level) and positive and we reject (at $1 \%$ level) the null hypothesis that the market premium and the

\footnotetext{
${ }^{16}$ This finding is consistent with the usual interpretation of a dividend yield related to the more persistent aspects
} of business conditions and a term spread related to a short-term variation in business conditions. 
prices of cross-effects of market risk factor and both instrumental variables are simultaneously equal to zero in both periods.

For the prices of exchange rate and inflation risks, we compute two different tests to determine whether both exchange rate/inflation risk premiums are simultaneously equal to zero and, if not, examine the significance of its components. The test results show that both common and residual exchange rate risk premiums in the pre-euro period, common and residual components in the pre-euro period, and common components in the post-euro period are jointly significant (at the $1 \%$ level). Both the UK inflation and excluding-UK inflation risk premiums, and the UK inflation and excluding-UK inflation components are jointly significant (at the 5\% level) in the pre- and post-euro periods. Besides, the (individual) common exchange rate, residual exchange rate, UK inflation and excludingUK inflation risks are significantly priced (at the 5\% level) in the pre-euro period, and the (individual) common exchange rate, residual exchange rate, UK inflation and excluding-UK inflation ones (also at the $5 \%$ level) in the post-euro period.

The results of specification tests are similar for country and sector and size-BM portfolios and we reject (at the 1\% level) all joint hypotheses for sector and size-BM sets. As regards the (individual) price of market, exchange rate and inflation risks, the following risks are not significantly priced (at the 10\% level): the market and common exchange rate risks in the pre- and post-euro periods respectively for the sector set; and the market and common exchange rate risks in both periods and the post-euro period respectively for the size-BM set.

These results give us some interesting insights. First, they show that common and residual components of currency risk (in reference to British pounds) are significantly priced in the pre-euro period. Hence European investors were rewarded by the exposure of their currency to UK currency (obviously related to the common component of currency risk), and for their exposure to other EUcountries currency risks (related to the residual component of currency risk). A conclusion which is consistent with the evidences presented by Carrieri (2001), but it contrasts with the De Santis, Gerard and Hillion's (2003) evidences about a EMU currency risk premium not jointly significant (at the 5\% level) for the period from January 1974 to December 1997. Second, European investors are significantly rewarded (at the 1\% level) for their exposure to UK (the reference country) and excluding-UK inflation risks. This factor of risk has been overlooked in previous studies and maybe (we investigate this issue in the next Subsection) it would have significant economic implications in pricing some portfolios. Finally, the extension of country set test results to sector and size-BM sets ones implies that not only do the currency and inflation risks explain cross-country but also withincountry differences in the returns of equities.

\subsection{ECONOMIC RELEVANCE OF MARKET, EXCHANGE RATE AND INFLATION RISKS}

The fact that exchange rate and inflation risks are significantly priced has important implications on pricing assets and hedging, but, the economic impact of this fact is dependent on how much an asset is exposed to these sources of risk. Therefore, a better assessment of this issue requires an explicit measure of the economic premium associated with each source of risk (see e.g., De Santis, Gerard and Hillion (2003)), which can be easily done decomposing the estimated excess total returns (see Eq. [5]) in the following parts:

$$
\begin{array}{ll}
\text { Market premia (MP): } & \gamma^{\mathrm{m}} \beta_{\mathrm{j}}^{\mathrm{m}}+\gamma^{\mathrm{m} \cdot \mathrm{div}} \beta_{\mathrm{j}}^{\text {m.div }}+\gamma^{\mathrm{m} \cdot \mathrm{term}} \beta_{\mathrm{j}}^{\mathrm{m} \cdot \text { term }} \\
\text { Currency premia }(\mathrm{CP})^{17}: & \gamma^{\lambda} \beta_{\mathrm{jk}}^{\lambda}+\gamma^{\mathrm{e}} \beta_{\mathrm{jk}}^{\mathrm{e}}+\gamma^{\lambda \cdot \text { div }} \beta_{\mathrm{jk}}^{\lambda \cdot \operatorname{div}}+\gamma^{\text {e.div }} \beta_{\mathrm{jk}}^{\text {e.div }}+\gamma^{\lambda \cdot \operatorname{term}} \beta_{\mathrm{jk}}^{\lambda \text {.term }}+\gamma^{\text {e.term }} \beta_{\mathrm{jk}}^{\text {e.term }}
\end{array}
$$

\footnotetext{
${ }^{17}$ In the post-euro period, the currency premia reduces to $\gamma^{\lambda} \beta_{\mathrm{jk}}^{\lambda}+\gamma^{\lambda \cdot \mathrm{div}} \beta_{\mathrm{jk}}^{\lambda \cdot \mathrm{div}}+\gamma^{\lambda \text {.term }} \beta_{\mathrm{jk}}^{\lambda \text {-erm }}$.
} 
Inflation premia (IP):

$$
\begin{aligned}
& \gamma^{\mathrm{i}} \beta_{\mathrm{jk}}^{\mathrm{i}}+\gamma^{\mathrm{D}} \beta_{\mathrm{jk}}^{\mathrm{D}}+\gamma^{\mathrm{i} \cdot \mathrm{div}} \beta_{\mathrm{jk}}^{\mathrm{i} \cdot \mathrm{div}}+\gamma^{\mathrm{D} \cdot \mathrm{div}} \beta_{\mathrm{jk}}^{\mathrm{D} \cdot \mathrm{div}}++\gamma^{\mathrm{i} \text {.term }} \beta_{\mathrm{jk}}^{\mathrm{i} \text {.term }}+\gamma^{\mathrm{D} \cdot \mathrm{term}} \beta_{\mathrm{jk}}^{\mathrm{D} \text {.term }} \\
& \gamma_{0}+\mathrm{MP}+\mathrm{CP}+\mathrm{IP}+\gamma^{\mathrm{div}} \beta_{\mathrm{j}}^{\text {div }}+\gamma^{\text {term }} \beta_{\mathrm{j}}^{\text {term }}
\end{aligned}
$$$$
\text { Total premia (TP): }
$$

We estimate each part using the conditional series of beta risks and gamma risk premiums obtained from the first and second stage of Fama and MacBeth's (1973) estimation of the AD-V model respectively. Finally, we compute the average and standard errors for the overall sample regressing the estimated premia on a constant, and the average and standard errors for the pre- and post-euro periods regressing the estimated premia on two dummies variables for the pre- and post-euro periods. Standard errors are computed using the Newey-West heteroskedasticity and autocorrelation robust procedure. Table 3 reports the average estimated risk premia and significance level of the country, sector and size-BM portfolios in the overall sample and the pre- and post-euro periods.

By and large, the market premia is economically significant in the overall sample and the pre- and post-euro period ${ }^{18}$ but the currency and inflation premia are economically significant only after the adoption of the single currency. Moreover, the results clearly show the differences in risk premia due to the characteristics of each portfolio. The average market risk premia is significant (at the $1 \%$ level) for Finland, France, Germany, the Netherlands and the United Kingdom portfolios, and for the ML, $\mathrm{MH}, \mathrm{HL}$ and HM size-BM portfolios in the overall sample and the pre- and post-euro periods. Concerning the currency and inflation premia, however the economic impact of currency and inflation risk premia is practically negligible for the three asset sets in the pre-euro period (the exceptions are Belgium, Portugal, Spain and Industrial portfolios for currency premia, and Ireland portfolio for inflation premia). The currency risk premia is economically significant (at the $5 \%$ level) and negative for Basic, Financial, Health, Non-Cyclical and Technology sector portfolios and the inflation risk premia is also economically significant (at the same level) and positive for Cyclical and Technology sectors in the post-euro period. Moreover, they represent a non-negligible fraction of the total premium. Consider the following examples to measure the economic relevance of these risk premia. Since the average currency risk premia of Basic sector portfolio in the period 1999-2004 is equal to $3.15 \%$ on an annual basis $(-0.002626 \times 12 \times 100)$, the total risk premia (also significant at $1 \%$ level) is reduced to $12.54 \%$. On the other side, the average inflation risk premia of Cyclical sector portfolio in the same period is equal to $2.70 \%$ on an annual basis and increases the total risk premia (also significant at $1 \%$ level) to $13.19 \%$. And the combined effect of the average currency risk premia ($2.54 \%$ ) with the average inflation risk premia $(9.51 \%)$ for Technology sector portfolio result in a total risk premia (no significant) of $11.70 \%$ on an annual basis. It is worthy of notice that these results are in contrast with the ones obtained by Carrieri (2001) and De Santis, Gerard and Hillion (2003) about a currency premia economically significant for country assets. Although we obtain evidence about a (common) currency premia economically significant and negative for some sector portfolio and the post-euro period that is comparable to the economically significant and negative non-EMU currency component premia reported by De Santis, Gerard and Hillion (2003) for country portfolios in the 1974-1997 period.

\subsection{THE ADOPTION OF EURO AND TIME-VARYING RISK PREMIUMS}

The economically significant currency and inflation premia for sector portolios after the adoption of the single currency is an interesting finding that requires an explanation. However the definitions of risk premia introduced earlier in the paper imply that each risk premia is affected by the effects of the Euro adoption and the characteristics of portfolio on the dynamics of its beta risk components and

\footnotetext{
${ }^{18}$ However, in our opinion these evidences must be re-analysed (and we will do in the Section 5) to consider the effect of a domestic risk significantly priced and economically significant in the pre-euro adoption period.
} 
their corresponding prices of risk. In this paper, we will restrict our study to individual effects (cross effects with instrumental variables will be omitted) of market, currency and inflation risk factors. To implement this analysis we calculate the average and Newey-West standard errors of the average of the conditional beta risk series of each (individual) risk and the corresponding conditional risk premium series in the overall sample period and the pre- and post-euro period. The former are estimated by regressing the corresponding serie on a constant, and the latter regressing the corresponding series on two dummies variables for the pre- and post-euro periods. Table 4 shows the average of the mean series of exposures to risk factors and significance level for the country, sector and size-BM portfolios in the overall sample and the pre- and post-euro periods in Panel A, and the same information but referred to the estimated prices of risk in Panel B.

The results about the exposure of equity assets to risks (see Table 4: Panel A) reveal that the beta risks with the exception of the averaged beta market risk are basically unchanged after the Euro adoption. Therefore, the dynamics of currency and inflation premia would be driven mainly by the dynamics of risk premium. To investigate these dynamics and establish, if they exist, the causality relationships between market, currency and inflation risk premiums; we estimate a multivariate VAR(1) model on the residuals series obtained by the projection of each risk premium on a constant, and the risk premium, the orthogonalized ${ }^{19}$ average of the conditional beta risk series of market, currency and inflation risks and the two instrumental variables lagged by one month for the pre- and post-euro periods. In order to get a better understanding of the main results in terms of the previous literature, we summarize the empirical results through the forecast variance decomposition and the "orthogonalized" impulse response ${ }^{20}$ of the common exchange rate risk premium and we centre around the effect on this of the (orthogonalized) inflation premium shocks conditioned to (orthogonalized) market and exchange rate risk premiums. Panel $\mathrm{C}$ of Table 4 reports the forecast error variance decomposition of the (orthogonalized) common exchange rate risk premiums of 6 and 24 months ahead using the Cholesky decomposition with the following order: (orthogonalized) market premium, common and residual exchange rate risk premiums, and UK inflation and excluding-UK inflation premiums for the country, sector and size-BM portfolios in the pre- and post-euro periods. Figure 2 plots the impulse response function of the (orthogonalized) common exchange rate risk premium to one standard deviation innovations of the (orthogonalized) UK inflation and excluding-UK inflation premiums given the (orthogonalized) market and currency premiums.

We start focus on the decomposition of the market risk premia. The exposure to the averaged market risks of the three asset sets is significant (at the 1\% level) and positive in the overall sample and pre- and post-euro periods. As regards the price of market risk, it is significant (at the $5 \%$ level) and positive for the country portfolios in the overall sample and pre-euro period, it is not significant (at the $5 \%$ level) and positive in the overall sample and pre-euro period for sector portfolios, and it is not significant (at the 10\% level) and negative for size-BM portfolios. Consequently, the economically

\footnotetext{
${ }^{19}$ The orthogonalized average of the conditional beta risk series of risk factors were obtained by regressing the average of the conditional beta risk series of each risk factor on a constant, and the own serie and the two instrumental variables lagged by one month.

${ }^{20}$ While the forecast error variance decomposition of a variable separates the variation in this variable into the components shocks to the VAR, the impulse response function of a variable traces the effect of a one-time shock to one of the innovations on current and future values of the variable.
} 
significant market premia is driven mainly by the exposure of equity assets to market risk and not by the dynamics of the market premium ${ }^{21}$.

Concerning the decomposition of the currency and the inflation risk premias, the averaged beta common exchange rate and UK and excluding-UK inflation risks of three asset sets are not significant at the $10 \%$ level in the overall sample and pre-euro period; the averaged beta common exchange rate for three asset sets is significant at $1 \%$ level and positive in the post-euro period; the averaged beta UK and excluding-UK inflation risks of sector portfolios are not significant at the $10 \%$ level in the posteuro period; the price of UK inflation, excluding-UK inflation risks of sector portfolios are significant at the 5\% level and negative in the post-euro period; and the price of common exchange rate risk of sector portfolios is not significant at the $10 \%$ level in the post-euro period. Consequently, the economically significant inflation and currency premias in the pre-euro period are driven mainly by the dynamics of the inflation and currency premiums. While the economically significant currency and inflation premias of sector portfolios in the post-euro period, in contrast, would be explained by the structural changes and causality patterns in the prices of common exchange rate and UK and excluding-UK inflation risks.

Our findings can be summarized as follows. In the post-euro period, only the common exchange rate risk premium (positive) of country set, and the UK inflation and the excluding-UK inflation risk premiums (negative) of sector set are significant at the 5\% level. In addition, the results in Table 4: Panel $\mathrm{C}$ and Figure 2 show a clear change in the patterns of causality between the risk premiums from the pre- to the post-euro periods. This change is characterized in all asset sets for an increase in the percentage of forecast error variance of the (orthogonalized) common exchange rate risk premiums explained by the (orthogonalized) inflation risk premiums, and in the impact (in absolute values) and persistence of the innovations of the (orthogonalized) inflation risk premiums on the (orthogonalized) common exchange rate risk premium. However, the impulse response functions have different shapes depending on the characteristics of each asset set. Specifically for sector set and post-euro period, we observe a high increase in the percentage of the 6- and 24-month ahead forescast error variance of the (orthogonalized) common exchange rate risk premium explained by the (orthogonalized) UK inflation premium in the region of $14 \%$, and a impact of the (orthogonalized) UK inflation premium up to 4month ahead on the common exchange rate risk premium in the region of $0.20 \%$.

To sum up, our evidence suggests that the economically significant and negative currency risk premia observed in 5 out of 10 sector portfolios after the Euro adoption is explained by the large positive impact of a large negative UK inflation premium on futures values of the common exchange rate premium combined with a small positive price of common exchange rate risk. In contrast, the economically significant inflation risk premia observed in 2 out of 10 sector portfolios from the combination of a statistically significant negative prices of UK and excluding-UK risks and very small risk exposures.

\section{ROBUSTNESS TESTS: EFFECT OF THE EUROPEAN STOCK MARKET DEGREE OF INTEGRATION}

The previous results are based on the assumption of a perfectly integrated European market consisting of the Euro Zone countries and the United Kingdom. But the European stock markets can exhibit some type of partial or full segmentation, that is, they can pay for a country-specific risk related with certain sources of risk that are not perfectly hedgeable, like differential tax treatment across countries, and for

${ }^{21}$ Carrieri's (2001) findings are just the opposite. A possible explanation for the discrepancy could be the GARCH methodology adopted for estimation and the assumed restriction on $\gamma_{t-1}$ to guarantee a positive market risk premium. 
a domestic risk domestically but not internationally diversifiable. In this section, we analyse whether the European stock markets are a completely integrated market and, if not, the effect of segmentation on pricing the market, currency and inflation risks. We proceed in stages. First, we consider the country set (the only one where we can distinguish between country assets) and we estimate a nationalized AD-V model with country-specific constants, in order to test whether these countryspecific risks and the domestic risk are equal to zero. Considering that the specific-country risks are practically negligible from the approval of the Treaty of Amsterdam, the rest of the results are based on the nationalized AD-V model (see Eq. [6]). Second, we estimate the nationalized AD-V model for three asset sets to provide a joint estimation of the domestic, market, currency and inflation risk premiums and to establish how the existence of a significant domestic risk premium explains the economic relevance of market, currency and inflation risks. The study finishes by measuring the degree of integration achieved by European stock markets and studying how this level of integration is affected by the currency and inflation risks.

\subsection{THE COUNTRY-SPECIFIC RISKS}

Let us consider and estimate ${ }^{22}$ for the country set the following augmented version of the nationalized AD-V model:

$$
\begin{aligned}
& \mathrm{E}\left(\mathrm{r}_{\mathrm{j}}\right)=\gamma_{0}^{\mathrm{j}}+\gamma^{\mathrm{m}} \beta_{\mathrm{j}}^{\mathrm{m}}+\gamma^{\mathrm{d}} \beta_{\mathrm{j}}^{\mathrm{d}}+\gamma^{\mathrm{i}} \beta_{\mathrm{j}}^{\mathrm{i}}+\gamma^{\mathrm{D}} \beta_{\mathrm{j}}^{\mathrm{D}}+\gamma^{\lambda} \beta_{\mathrm{j}}^{\lambda}+\gamma^{\mathrm{e}} \beta_{\mathrm{j}}^{\mathrm{e}}+\gamma^{\mathrm{m} \cdot \mathrm{div}} \beta_{\mathrm{j}}^{\mathrm{m} \cdot \mathrm{div}}+\gamma^{\mathrm{d} \cdot \mathrm{div}} \beta_{\mathrm{j}}^{\mathrm{d} \cdot \mathrm{div}} \\
& +\gamma^{\text {i.div }} \beta_{\mathrm{j}}^{\text {i.div }}+\gamma^{\text {D.div }} \beta_{\mathrm{j}}^{\text {D.div }}+\gamma^{\lambda \cdot \operatorname{div}} \beta_{\mathrm{j}}^{\lambda \cdot \text { div }}+\gamma^{\text {e.div }} \beta_{\mathrm{j}}^{\text {e.div }}+\gamma^{\text {m.term }} \beta_{\mathrm{j}}^{\text {m.term }}+\gamma^{\text {d.term }} \beta_{\mathrm{j}}^{\text {d.term }} \\
& +\gamma^{\text {i.term }} \beta_{j}^{\text {i.term }}+\gamma^{\text {D.term }} \beta_{j}^{\text {D.term }}+\gamma^{\lambda \cdot \text { term }} \beta_{j}^{\lambda \cdot \text { term }}+\gamma^{\text {e.term }} \beta_{j}^{\text {e.term }}+\gamma^{\text {div }} \beta_{j}^{\text {div }}+\gamma^{\text {term }} \beta_{j}^{\text {term }}
\end{aligned}
$$

Where $E\left(r_{j}\right)$ is the expected excess of country portfolio $j$ expressed in British pounds and $\gamma_{0}^{j}$ is the specific risk of country $\mathrm{j}$. In addition, we compute two different Wald specification tests to determine whether specific-country and domestic risks are simultaneously equal to zero and to examine the significance of each component in the pre- and post-euro periods. Finally, we complete the analysis implemented by a direct test of structural change for analyzing the hypothesis that whether the approval of the Treaty of Amsterdam and/or the adoption of the single currency has affected the average specific risk of each country. This test is implemented regressing the estimated specificcountry series on a constant or two dummies variables in the overall and pre- and post-euro periods respectively. Table 5 summarizes the results of these analyses ${ }^{23}$. In Panel A, we report the Wald test statistics to evaluate the joint hypothesis on specific-country and domestic risks. And in Panel B, we show the average estimated country-specific risks and significance level (with the Newey-West correction) of each country and the average of all countries in the overall sample, the pre- and postapproval of Treaty of Amsterdam periods and the pre- and post-euro periods.

Our findings can be summarized as follows. In the pre-euro period, we reject at the $1 \%$ level the joint hypothesis of specific-country and domestic risks equal to zero, specific-country risks equal to zero and domestic risks equal to zero. However, we accept all these hypothesis at the $10 \%$ level for post-euro period. Similarly, the specific-country risk is statistically significant (at the $1 \%$ level) in the average of all countries and in 9 out of 10 countries for the pre-euro period whereas it is not statistically significant (at the 5\% level) in the average of all countries and in 7 out 12 countries for the post-euro period. Hence, we can neither reject the hypothesis of a fully segmented European market

\footnotetext{
${ }^{22}$ The risk premiums are estimated using the OLS method because of the unequal size of the specific-country risk series.

${ }^{23}$ For reason of space, we do not report the cross-sectional estimated risk premiums for the "augmented" nationalized $\mathrm{AD}-\mathrm{V}$ model and the additional specification tests but they are available from the authors.
} 
nor reject the existence of jointly significant specific-country risks for the pre-euro period. However, the country-specific risk series have decreased through the whole sample and after the approval of the Treaty of Amsterdam, the specific-country risk is not statistically significant (at the 5\% level) in the average of all countries and in 6 out of 12 countries. Consequently, we can consider that the specificcountry risks are practically negligible from the approval of the Treaty of Amsterdam and the nationalized AD-V model (see Eq. [6]) is a good approach to analyse the level of integration of European stock markets.

\subsection{THE DOMESTIC RISK: PRICE OF RISK AND EFFECTS ON ASSET PRICING}

Panel A of Table 6 reports the Wald test statistic of the nationalized AD-V model ${ }^{24}$ (see Eq. [6]) to evaluate whether the domestic risks are equal to zero for country, sector and size-BM portfolios in the pre- and post-euro periods. We reject the joint hypothesis of all domestic risk premiums equal to zero at the $1 \%$ level for the three asset sets in the pre- and the post-euro periods. Moreover, the (individual) price of domestic risk is significant at the $1 \%$ level and negative for three asset sets in the pre-euro period and for the country and sector portfolios in the post-euro period. The rest of the specification tests give similar results to the ones reported for the $\mathrm{AD}-\mathrm{V}$ model, the only difference is that now the excluding-UK inflation risks are not significant (at the $10 \%$ level) for the country portfolios in the post-euro period. Consequently, the European stock markets are not fully integrated and we must revise the previous results to measure the effect of the domestic, market, currency and inflation risks on the pricing of equities.

Tables 6 and 7, and Figure 3 summarize our results from the nationalized AD-V model and the estimation of a multivariate VAR(1) model on the residuals series obtained by the projection of each risk premium serie from this model on a constant, and the risk premium, the orthogonalized average of the conditional beta risk series of market, currency and inflation risks and the two instrumental variables lagged by one month for the pre- and post-euro periods. As before, the results from VAR analysis are centred around the effect on the (orthogonalized) common exchange rate risk premium of the (orthogonalized) inflation premium shocks conditioned to (orthogonalized) market and exchange rate risk premiums. In Panel B of Table 6, we report the average of the estimated prices of (individual) market, domestic, exchange rate and inflation risks and their significance level (with the Newey-West correction) for the country, sector and size-BM portfolios in the whole sample and the pre- and posteuro periods. Panel $\mathrm{C}$ of Table 6 shows the forecast error variance decomposition of the (orthogonalized) common exchange rate risk premiums of 6 and 24 months ahead using the Cholesky decomposition with the following order: (orthogonalized) market premium, common and residual exchange rate risk premiums, UK inflation and excluding-UK inflation premiums and domestic premium for the three asset sets in the pre- and post-euro periods. Table 7 reports the average market, domestic, inflation, currency and total estimated risk premia ${ }^{25}$ and significance level (with the NeweyWest correction) for the country, sector and size-BM portfolios for the overall sample and the pre- and post-euro periods. Figure 3 plots the impulse-response function of the (orthogonalized) common exchange rate risk premium to one standard deviation innovations of the (orthogonalized) UK

\footnotetext{
${ }^{24}$ For reason of space, we do not report the cross-sectional estimated of risk premiums for the nationalized $\mathrm{AD}-\mathrm{V}$ model and the additional specification tests but they are available from the authors.

${ }^{25}$ The definitions of market, currency and inflation premia are the ones presented in subsection 4.2. The domestic premia (DP) is equal to $\gamma^{\mathrm{d}} \beta_{\mathrm{j}}^{\mathrm{d}}+\gamma^{\mathrm{d} d \mathrm{div}} \beta_{\mathrm{j}}^{\mathrm{d} d \mathrm{div}}+\gamma^{\mathrm{d} \text { derm }} \beta_{\mathrm{j}}^{\mathrm{d} \text { term }}$, and the total premia is equal to $\gamma_{0}+\mathrm{MP}+\mathrm{CP}+\mathrm{IP}+\mathrm{DP}+\gamma^{\text {div }} \beta_{\mathrm{j}}^{\text {div }}+\gamma^{\text {term }} \beta_{\mathrm{j}}^{\text {term }}$.
} 
inflation, excluding-UK inflation and domestic premiums given the (orthogonalized) market and currency premiums.

To sum up, the inclusion of domestic risk in the pricing equation produces an increase in the number of currency and inflation risk premiums economically significant and a correction in the sign of the estimated total premia (only 5 cases remain economically significant and negative in the preeuro period). The currency and inflation premia are significant at the $5 \%$ level negative and positive respectively in 7 out of 10 sector portfolios as follows -Basic, Cyclical, Financial, Health, Industrial, Non-Cyclical and Technology sectors in the post-euro period; the currency premium is economically significant at the 5\% level and positive for Health and Industrial sector portfolios in the pre-euro period and MH size-BM portfolio in the post-euro period; and the inflation premia is significant at the 5\% level for Austria and Ireland portfolios in the pre-euro period. Reviewing the previous examples, the combined effect of the average currency risk premia of $-3.41 \%(/-1.93 \% /-2.99 \%)$ with the average inflation risk premia of $6.14 \%(/ 7.77 \% / 19.44 \%)$ for Basic (/Cyclical /Technology) sector portfolio increases the total risk premia to $11.88 \%(/ 12.83 \% / 9.78 \%)$ on an annual basis.

Concerning the decomposition of the market, currency and inflation risk premia, the conclusions about the average estimated prices of risk for the AD-V and nationalized AD-V models are practically the same with the exception of price of excluding-UK inflation of sector portfolios that is not significant at 5\% level in the post-euro period. Therefore, the explanations about a significant market and inflation risk premias remain the same. While the difference between previous and actual results for currency risk premia seem to be due to the effect of the (orthogonalized) domestic risk premium on the causality patterns in the prices of common exchange rate and UK and excluding-UK inflation risks throughout the post-euro period. The results show three mainly differences referred to the post-euro period: the increase in the percentage of forecast error variance of the (orthogonalized) common exchange rate risk premium explained by the (orthogonalized) domestic risk premium for sector portfolios; a reduction of the effect on the future values of the (orthogonalized) common exchange rate risk premium of the three asset sets to the shocks of the innovations of the (orthogonalized) UK inflation risk premium followed by an increase of the effect on the future values of the (orthogonalized) common exchange rate risk premium of country and sector porfolios to the shocks of the innovations of the (orthogonalized) excluding-UK inflation risk premium; and a negative response of the (orthogonalized) common exchange rate risk premium of three asset sets to one standard deviations of the (orthogonalized) domestic risk premium.

In conclusion, our evidence suggest that the economically significant and negative currency risk premia observed in 7 out of 10 sector portfolios after the Euro adoption is explained by the large positive impact of a large negative UK inflation premium (the domestic and excluding-UK risk premium are small) on futures values of the common exchange rate premium combined with a small positive price of common exchange rate risk. In contrast, the economically significant inflation risk premia observed in the same 7 out of 10 sector portfolios from the combination of a statistically significant negative price of UK inflation risk and a very small risk exposure. 


\subsection{THE EUROPEAN STOCK MARKET DEGREE OF INTEGRATION}

We have concluded that the European stock markets are not fully integrated in the pre- and post-euro period because the European investors are significantly rewarded for a domestic risk. However, we also observe a higher level of integration in the post-euro period; the Wald statistics are smaller and the price of the (individual) domestic risk of size-BM portfolios is not significant. In this situation, two subjects require an additional study: the economic relevance of domestic risk to evaluate the impact of the lack of integration of European stock markets in pricing assets, and the effect of currency and inflation risk on the European stock market degree of integration.

To implement this study we will use the results summarized in Tables 6, 7 and 8, and Figure 4. And we will re-examine the results of the estimated VAR(1) model on the (orthogonalized) risk premiums of the nationalized AD-V model centring around the effect on the (orthogonalized) domestic premium of the (orthogonalized) currency and inflation premium shocks conditioned to (orthogonalized) market and domestic risk premiums. Table 8 shows the forecast error variance decomposition of the (orthogonalized) domestic premium of 6 and 24 months ahead using the Cholesky decomposition with the following order: (orthogonalized) market premium, domestic premium, common and residual exchange rate and UK inflation and excluding-UK inflation risk premiums for the three asset sets in the pre- and post-euro periods. Figure 4 plots the impulse-response function of the (orthogonalized) domestic risk premium to one standard deviation innovations of the (orthogonalized) UK inflation, excluding-UK inflation, common exchange rate and residual exchange rate premiums given the (orthogonalized) market and domestic premiums.

Generally, the adoption of the single currency has reduced the number of domestic risk premium economically significant (see Table 7) and consequently the European stock markets are more integrated. The domestic risk premia is significant at the $5 \%$ level and negative in the pre-euro period in 5 out of 12 country portfolios, 3 out of 10 sector portfolios and 3 out of 9 size-BM portfolios as follows -Finland, France, Germany, the Netherlands, UK, Basic, Cyclical, Financial, MH, HL and HM portfolios. Whereas, it is significant at the $5 \%$ level and negative in the post-euro period in 0 out of 12 country portfolios, 2 out 10 sector portfolios and 4 out 9 size-BM portfolios as follows Financial, Health, LH, ML, MM and MH portfolio.

The explanation of these findings is not easy. In the pre-euro period, the domestic beta risks of the porfolios ${ }^{26}$ with significantly domestic premia are significant at the $1 \%$ level and positive and the price of domestic risk of the three asset sets is significant and negative (see Table 6: Panel B).Consequently, the economically significant and negative domestic risk premia in pre-euro period is explained by the combination of a statistically significant negative domestic risk premium and a statistical significant positive risk exposure. While in the post-euro period, we observe a higher exposure to domestic risk (the average of the domestic risks is significant at the $1 \%$ level for three asset sets -see Panel A in Table 4) together with a no significant (at the 5\% level) price of risk for all three asset sets which cannot explain the differences of economic relevance of domestic risk between the country portfolios and the sector and size-BM asset sets. Hence, the explanation of the economically significant domestic risk premium would be explained by the differences in the patterns of causality between domestic, currency and inflation premiums between asset sets.

Our findings (see Table 8 and Figure 4) can be summarized as follows. The increase of the percentage of forecast error variance of the (orthogonalized) domestic risk premium explained by the

\footnotetext{
${ }^{26}$ For reasons of space, we do not report the average of the domestic beta risks for each country, sector and sizeBM portfolio and its level of significance (with the Newey-West correction) in the overall sample and the preand post-euro adoption periods but they are available from the authors.
} 
(orthogonalized) UK inflation, excluding-UK inflation and common exchange rate premiums is generally higher for sector and size-BM portfolios. In addition, the impulse response functions of the (orthogonalized) domestic risk premium given the (orthogonalized) market and domestic risk premiums have different shapes depending on the characteristics of each asset set. Specifically, the effect of the (orthogonalized) UK inflation risk premium up to 9-month-ahead is positive for all asset sets; the effect of the (orthogonalized) excluding-UK inflation risk premium up to 6-month-ahead is negative for country portfolios whereas it is positive (and very large in sector set) for sector and sizeBM portfolios; and the effect of the (orthogonalized) common exchange rate risk premium up to 5month-ahead is negative for size-BM portfolios whereas it is positive (and very large in sector set) for both country and sector portfolios. In conclusion, the economically significant domestic risk premium of sector portfolios after the adoption of the single currency is explained by a large and positive exposure to domestic risk and a small negative price of domestic risk combined with the effect of a significant (at the 5\% level) and negative UK inflation risk premium and a no significant excludingUK inflation risk premium on futures values of the domestic risk premium. While the economically significant domestic risk premium for size-BM portfolios in the post-euro period is explained by a large and positive exposure to domestic risk and a small negative price of domestic risk combined with the effect of a small and negative UK and excluding-UK inflation risk premiums and a small positive common exchange risk premium on futures values of the domestic risk premium.

By and large, our results about the process of integration of European stock markets are consistent with the ones presented by Hardouvelis, Malliaropulos and Priestley (2006). The degree of integration of stock markets towards a fully integrated market has clearly increased after the adoption of the single currency being not significant the domestic risk premia in the post-euro period. Moreover the effect of inflation risks, Hardouvelis, Malliaropulos and Priestley (2006) considered the inflation differential a major indicator of the ability to achieve convergence, explains in part the remaining significantly economically domestic risk premia of some sector and size-BM portfolios.

\section{CONCLUSION}

In this paper, we attempt to measure the effects of exchange rate and inflation risk factors on asset pricing in the EU stock markets and study how the adoption of the single currency has affected the causal relationships between the prices of these risks. In this context, the relevant issues are analysing whether the inflation risks are significantly priced and, if they are, how they affect or not to the price of currency risks, and how much the investors are rewarded for their exposure to inflation and currency risks. Besides, this study assumes asset pricing in an international setting so we also evaluate how these results can be affected by the European stock market degree of integration. The main findings can be summarized as follows.

- Exchange rate and inflation risks are significantly priced. Both common and residual exchange rate risk premiums in the pre-euro period, common and residual components in the pre-euro period, and common components in the post-euro period are jointly significant. Moreover, both the UK inflation and excluding-UK inflation risk premiums, and the UK inflation and excludingUK inflation components are jointly significant in the pre- and post-euro periods.

- The size of exchange rate and inflation risk premia are economically significant. Whereas the economic impact of currency and inflation risk premia is practically negligible for the three asset sets in the pre-euro period. The currency risk premia is economically significant and negative for Basic, Financial, Health, Non-Cyclical and Technology sector portfolios, and the inflation risk premia is also economically significant and positive for Cyclical and Technology sectors in the post-euro period. 
- In the post-euro period, the dynamics of inflation risk premiums explain in part the economic impact on returns of both exchange and inflation risk factors. The economically significant and negative currency premia observed in sector portfolios after the Euro adoption is explained by the large positive impact of a large negative UK inflation premium on futures values of the common exchange rate premium combined with a small positive price of common exchange rate risk. In contrast, the economically significant inflation premia from the combination of statistically significant negative prices of inflation risks and very small risk exposures.

- However the European stock markets are not fully integrated, this lack of integration does not affect the previous results in essence. The joint hypothesis of all domestic risk premiums equal to zero is rejected for the three asset sets in the pre- and post-euro periods. Moreover, the domestic risk premia is significant in 5 out of 12 country portfolios, 3 out of 10 sector portfolios and 3 out of 9 size-BM portfolios in the pre-euro period; and in 0 out of 12 country portfolios, 2 out 10 sector portfolios and 4 out 9 size-BM portfolios in the post-euro period. Consequently, the European stock markets are not fully integrated. The inclusion of domestic risk in the pricing equation produces an increase in the number of economically significant currency and inflation risk premiums but the decomposition of the exchange rate and inflation risk premia remain the same.

- The degree of integration of EU stock markets has increased after the adoption of the single currency. The Wald statistics are smaller, the price of the (individual) domestic risk of size-BM portfolios is not significant and the domestic risk premia is only significant in 6 out 31 portfolios.

- The dynamics of inflation and currency risk premiums explain in part the economically significant domestic risk premium in the post-euro period. The economically significant and negative domestic risk premia in pre-euro period is explained by the combination of a statistically significant negative price of the domestic risk and a statistical significant positive risk exposure. In contrast, it is explained in the post-euro period by a large and positive exposure to domestic risk and a small negative price of domestic risk combined with the effect of inflation and EUR/GBP exchange rate risk premiums on futures values of the domestic risk premium.

- Overall, overlooking inflation risk factors can produce an under/overestimation of the currency premiums and a miscalculation of the degree of integration of EU stock markets.

In conclusion, the adoption of the single currency has eliminated the EU currency risks but it has not reduced the expected returns on EU plus UK equities. Moreover, the elimination of EU currency risks has been offset by an increase in the EUR/GBP exchange rate and inflation risk premia that it is explained, almost in part, by an increase of the relevance of inflation premium shocks on future values of currency. Futhermore, these inflation premium shocks also contributes to make the domestic risk premium economically significant in the post-euro period and consequently to reduce the achievable level of integration. Future research includes the construction of a mimicking portfolio to capture news related to future UK and excluding-UK inflation risk premiums and the analysis of the factors that might affect the growht of these premiums from the Euro adoption. 


\section{REFERENCES}

Adler, M. and Dumas, B., 1983. International Portfolio Choice and Corporation Finance: A synthesis. Journal of Finance, 38(3), 925-984.

Black, F., 1972. Capital Market Equilibrium with Restricted Borrowing. Journal of Business, 45, 444-455.

Carrieri, F., 2001. The Effects of Liberalization on Market and Currency Risk in the European Union. European Financial Management 7, 259-290.

Cochrane, J. H., 1996. A Cross-Sectional Test of an Investment based Asset Pricing Models. Journal of Political Economy, 104, 572-621.

Dahlquist, M. and Sällström, T., 2002. An Evaluation of International Asset Pricing Models. Working Paper (Duke University, Durham, NC).

De Santis, G. and Gerard, B., 1997. International Asset Pricing and Portfolio Diversification with Time-Varying Risk. Journal of Finance, 52, 1881-1912.

De Santis, G., Gérard, B. and Hillion P., 2003. The Relevance of Currency Risk in the EMU. Journal of Economics and Business, 55, 427-462.

Dumas, B. and Solnik, B., 1995. The World Price of Foreign Exchange Risk. Journal of Finance, 50(2), 445479.

Fama, E. F. and French, K. R., 1988. Dividend Yields and Expected Stock Returns. Journal of Financial Economics, 22, 3-27.

Fama, E. F. and French, K. R., 1989. Business Conditions and Expected Returns on Stocks and Bonds. Journal of Financial Economics, 25, 23-49.

Fama, E. F and French, K. R. 1998. Value versus Growth: The International Evidence. Journal of Finance, 53, 1975-1999.

Fama, E. F and Gibbons, M.R. 1984. A Comparison of Inflation Forecasts. Journal of Monetary Economics, 13, 327-348.

Fama, E. F. and MacBeth, J. D., 1973. Risk, Return, and Equilibrium: Empirical Tests. Journal of Political Economy, 81, 607-636.

Ferson, W. and Harvey, C. 1991. The Variation of Economic Risk Premiums. Journal of Political Economics, 99, 385-415.

Ferson, W. and Harvey, C. 1999. Conditioning Variables and the Cross Section of Stock Returns. Journal of Finance, 54, 1325-1360.

Grauer, F. L. A., Litzenberger, R. H. and Stehle, R. S., 1976. Sharing Rules and Equilibrium in an International Capital Market under Uncertainty. Journal of Financial Economics, 3, 233-256.

Hardouvelis, G. A., Malliaropulos, D. and Priestley, R., 2006. EMU and European Stock Market Integration. Journal of Business, 79, 365-392.

Jorion, P., 1991. The Pricing of Exchange Risk in the Stock Market. Journal of financial and quantitative analysis, 26, 363-376.

Karolyi, G. A. and Stulz, R. M. 2003. Are Financial Assets Priced Locally or Globally? Handbook of the Economics of Finance, 975-1020.

Newey, W. and West, K. 1987. A Simple Positive Semi-Definite, Heteroskedasticity and Autocorrelation Consistent Covariance Matrix. Econometrica, 55, 703-708.

Sercu, P., 1980. A Generalization of the International Asset Pricing Model. Revie de l'Association Française de Finance, 1, 91-135.

Solnik, B. H., 1974. An Equilibrium Model of the International Capital Market. Journal of Economic Theory, 8, 500-524.

Solnik, B. H., 1977. Testing International Asset Pricing: Some Pessimistic Views. Journal of Finance, 32, 503511. 
Stehle, R., 1977. An Empirical Test of the Alternative Hypothesis of National and International Pricing of Risky Assets. Journal of Finance, 32, 493-502.

Stulz, R. M., 1995. International Portfolio Choice and Asset Pricing: An Integrative Survey. Handbook in OR \& MS, 9, 201-223.

Vassalou, M., 2000. Exchange Rate and Foreign Inflation Risk Premiums in Global Equity Returns. Journal of International Money and Finance, 19, 433-470.

Zhang, X., 2006. Specification Tests of International Asset Pricing Models. Journal of International Money and Finance, 25, 275-307. 


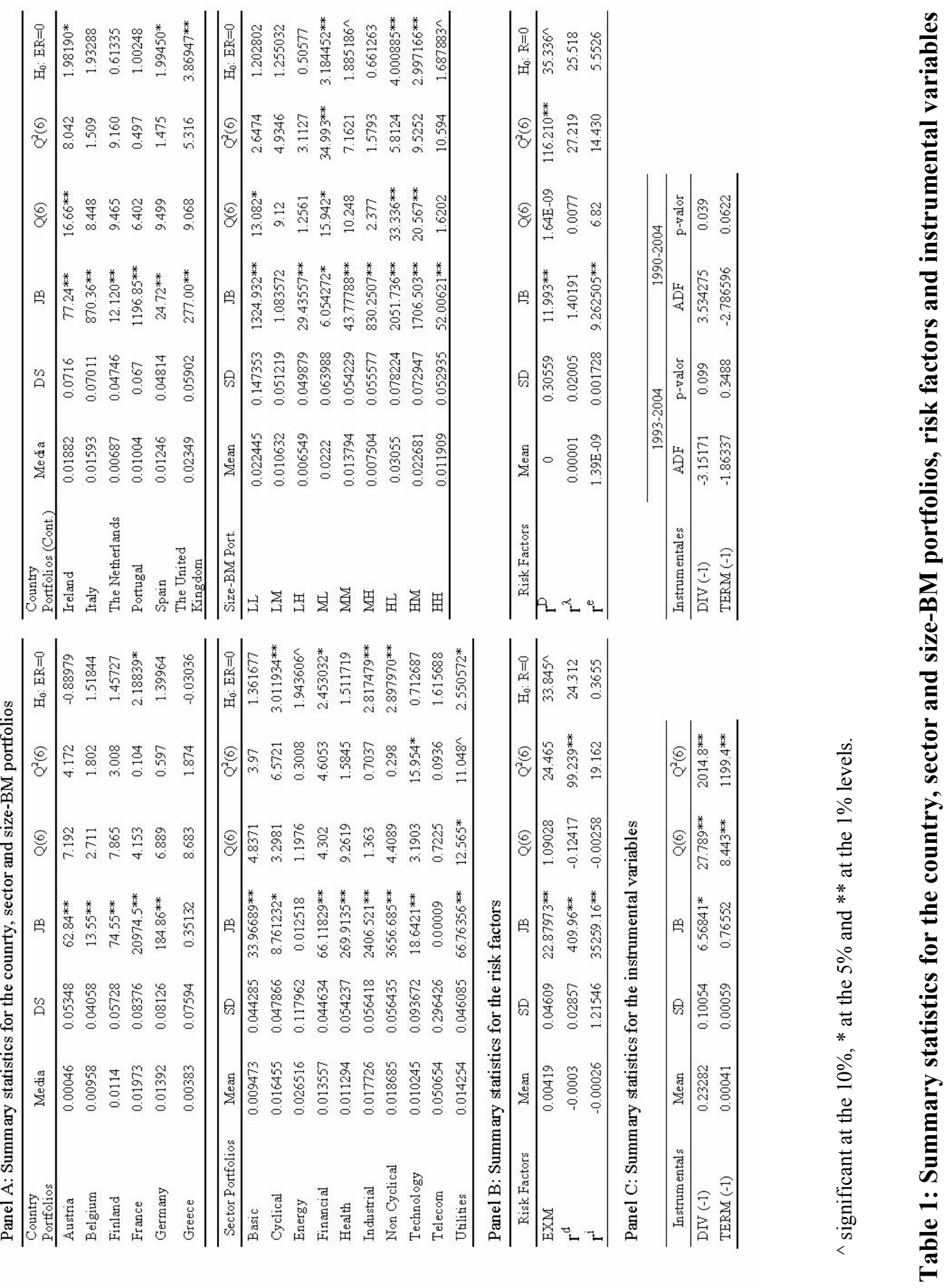



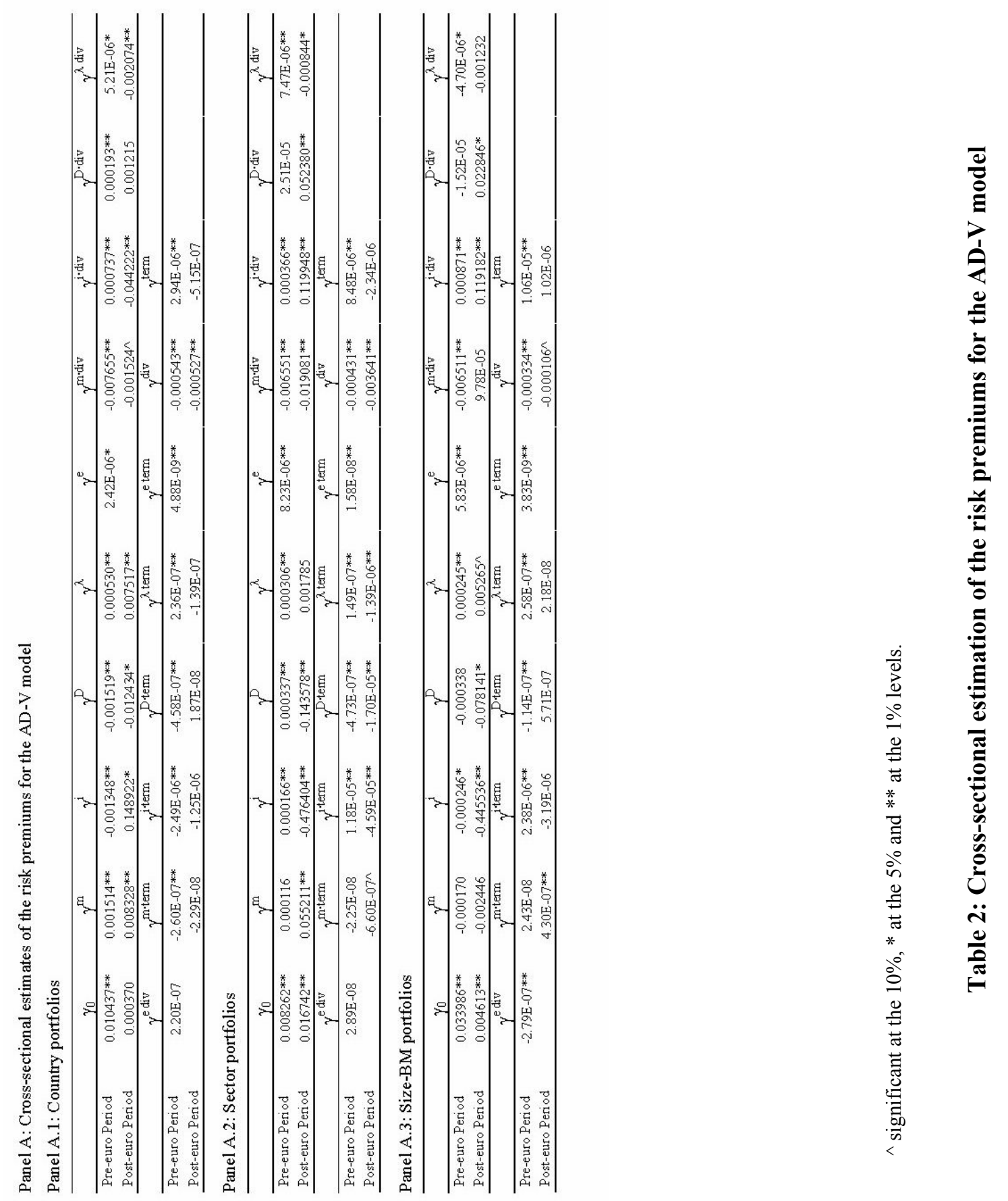

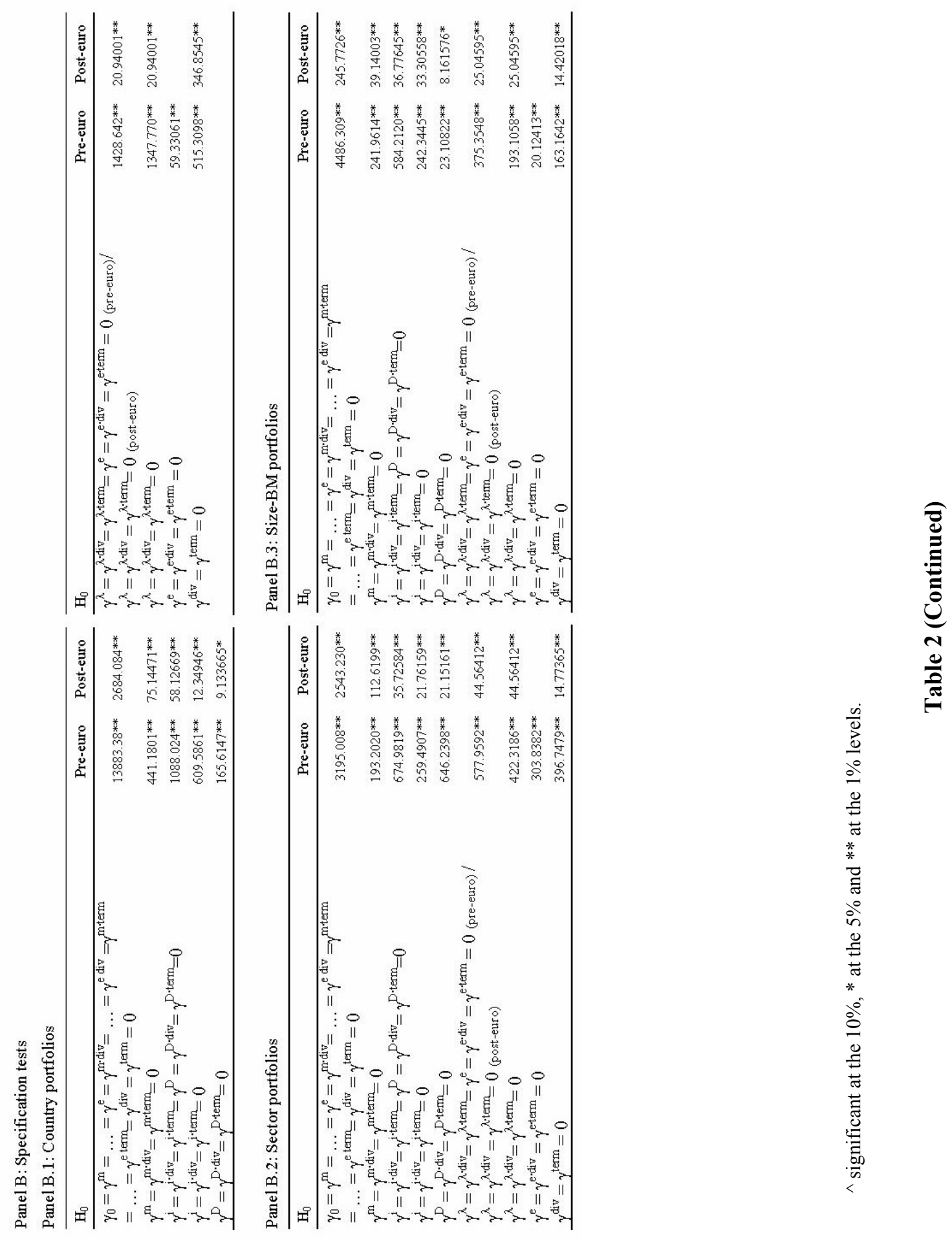
Panel A: Average estimated economic risk premiums for the country portfolios

Panel A.1: Overall

\begin{tabular}{lcccc}
\hline Risk premia & Market & Inflation & Currency & Total \\
\hline Austria & -0.000302 & -0.000282 & -0.000636 & 0.004002 \\
Belgium & 0.096218 & 0.000167 & $0.000357^{\wedge}$ & 0.103232 \\
Finland & $-0.067366^{* *}$ & 0.003986 & -0.00088 & $-0.061643^{* *}$ \\
France & $-0.022452^{* *}$ & 0.001439 & 0.000177 & $-0.016376^{*}$ \\
Germany & $-0.025633^{* *}$ & 0.001869 & 0.000056 & $-0.019415^{*}$ \\
Greece & 0.005954 & 0.310634 & 0.013378 & 0.331596 \\
Ireland & -0.012474 & 0.001361 & 0.032122 & 0.019667 \\
Italy & -0.014429 & 0.000925 & 0.000866 & -0.007554 \\
The Netherlands & $-0.019981^{* *}$ & 0.001127 & -0.000324 & $-0.014542^{*}$ \\
Portugal & 0.169694 & 0.000447 & $0.000771^{* *}$ & 0.178872 \\
Spain & 0.204089 & 0.001768 & $0.000768^{* *}$ & 0.213296 \\
The United Kingdom & $-0.012569^{* *}$ & 0.001518 & -0.000413 & -0.006776 \\
\hline
\end{tabular}

Panel A.2: Pre-euro Period

\begin{tabular}{|c|c|c|c|c|}
\hline Risk premia & Market & Inflation & Currency & Total \\
\hline Austria & -0.002347 & -0.000559 & -0.002031 & 0.005218 \\
\hline Belgium & 0.191299 & 0.0000522 & $0.000424 *$ & 0.204429 \\
\hline Finland & $-0.137634 * *$ & 0.007792 & -0.002233 & $-0.127237 * *$ \\
\hline France & $-0.047939 * *$ & 0.003152 & -0.001137 & $-0.037336 * *$ \\
\hline Germany & $-0.055831 * *$ & 0.003693 & -0.000677 & $-0.044647 * *$ \\
\hline Greece & $-0.005049 * *$ & 0.003012 & 0.004518 & 0.002129 \\
\hline Ireland & $-0.001759^{\wedge}$ & $-0.006608^{*}$ & 0.115819 & 0.107748 \\
\hline Italy & -0.033905 & 0.001498 & 0.001641 & -0.020659 \\
\hline The Netherlands & $-0.043011 * *$ & 0.002476 & -0.001113 & $-0.032794 * *$ \\
\hline Portugal & 0.338598 & 0.000693 & $0.000805^{* *}$ & 0.355701 \\
\hline Spain & 0.408481 & 0.003611 & $0.001083^{* *}$ & 0.426224 \\
\hline The United Kingdom & $-0.027038 * *$ & 0.002117 & -0.000994 & $-0.016922 *$ \\
\hline \multicolumn{5}{|c|}{ Panel A.3: Post-euro Period } \\
\hline Risk premia & Market & Inflation & Currency & Total \\
\hline Austria & $0.001742 * *$ & -0.00000468 & 0.000758 & 0.002786 \\
\hline Belgium & $0.002458 * *$ & 0.00028 & 0.000291 & $0.00344 *$ \\
\hline Finland & $0.002901 * *$ & 0.000181 & 0.000473 & $0.003951^{*}$ \\
\hline France & $0.003035^{* *}$ & -0.000275 & $0.001492^{\wedge}$ & $0.004584 *$ \\
\hline Germany & $0.004565 * *$ & 0.0000455 & $0.000789^{\wedge}$ & $0.005818^{* *}$ \\
\hline Greece & 0.007635 & 0.357632 & 0.014732 & 0.381931 \\
\hline Ireland & -0.015896 & 0.003907 & 0.005385 & -0.00847 \\
\hline Italy & $0.003424 * *$ & 0.0004 & 0.000156 & $0.004459^{*}$ \\
\hline The Netherlands & $0.00305^{* *}$ & -0.000222 & 0.000465 & $0.003711^{*}$ \\
\hline Portugal & $0.003136^{* *}$ & 0.000204 & 0.000737 & $0.004499 *$ \\
\hline Spain & $0.002536^{* *}$ & -0.000049 & 0.000458 & $0.003326^{\wedge}$ \\
\hline The United Kingdom & $0.0019 * *$ & $0.00092^{\wedge}$ & 0.000169 & $0.00337^{*}$ \\
\hline
\end{tabular}

$\wedge$ significant at the $10 \%, *$ at the $5 \%$ and $* *$ at the $1 \%$ levels.

Table 3: Average estimated economic risks premiums from the AD-V model 
Panel B: Average estimated economic risk premiums for the sector portfolios

Panel B.1: Overall

\begin{tabular}{lcccc}
\hline Risk premia & Market & Inflation & Currency & Total \\
\hline Basic & $-0.018537^{* *}$ & 0.000418 & -0.00033 & -0.008026 \\
Cyclical & $-0.011559^{* *}$ & -0.000123 & -0.000594 & -0.001277 \\
Energy & 0.001698 & -0.001927 & $-0.00379^{\wedge}$ & 0.007917 \\
Financial & $-0.049197^{* *}$ & 0.00071 & 0.001493 & $-0.03968^{* *}$ \\
Health & 0.12619 & $0.002293^{*}$ & $-0.001043^{\wedge}$ & 0.140273 \\
Industrial & -0.226785 & 0.000549 & -0.000241 & -0.212931 \\
Non Cyclical & -0.003377 & 0.000453 & -0.000988 & 0.022968 \\
Technology & $-0.022867^{* *}$ & 0.003129 & -0.005805 & 0.004902 \\
Telecom & 0.019179 & -0.002183 & -0.002128 & 0.01741 \\
Utilities & 0.137411 & 0.000597 & $-0.001157^{\wedge}$ & 0.152012 \\
\hline
\end{tabular}

Panel B.2: Pre-euro Period

\begin{tabular}{lcccc}
\hline Risk premia & Market & Inflation & Currency & Total \\
\hline Basic & $-0.032852^{* *}$ & -0.0007 & 0.001966 & $-0.026505^{* *}$ \\
Cyclical & $-0.017969^{* *}$ & -0.002492 & 0.000377 & $-0.013544^{*}$ \\
Energy & -0.010736 & -0.006247 & -0.008385 & -0.017193 \\
Financial & $-0.094434^{* *}$ & -0.001099 & 0.005219 & $-0.091491^{* *}$ \\
Health & 0.259691 & 0.00096 & 0.000307 & 0.271516 \\
Industrial & -0.451633 & -0.000342 & $0.00126^{*}$ & -0.439325 \\
Non Cyclical & -0.003493 & -0.000268 & 0.000935 & 0.036998 \\
Technology & $-0.040207^{* *}$ & -0.002722 & -0.010311 & -0.001018 \\
Telecom & $-0.02911^{\wedge}$ & -0.018922 & -0.040222 & $-0.081042^{*}$ \\
Utilities & 0.279339 & 0.001909 & 0.0000142 & 0.294935 \\
\hline
\end{tabular}

Panel B.3: Post-euro Period

\begin{tabular}{lcccc}
\hline Risk premia & Market & Inflation & Currency & Total \\
\hline Basic & -0.004221 & $0.001536^{\wedge}$ & $-0.002626^{*}$ & $0.010454^{* *}$ \\
Cyclical & -0.005149 & $0.002247^{*}$ & $-0.001566^{\wedge}$ & $0.010989^{* *}$ \\
Energy & 0.007742 & 0.000173 & -0.001556 & $0.020124^{\wedge}$ \\
Financial & -0.003959 & $0.00252^{\wedge}$ & $-0.002232^{*}$ & $0.01213^{* *}$ \\
Health & -0.005456 & $0.003608^{\wedge}$ & $-0.002374^{*}$ & $0.010852^{*}$ \\
Industrial & -0.005059 & $0.001428^{\wedge}$ & $-0.00172^{\wedge}$ & $0.010318^{* *}$ \\
Non Cyclical & -0.003282 & $0.001045^{\wedge}$ & $-0.002563^{*}$ & $0.011471^{* *}$ \\
Technology & -0.008658 & $0.007924^{*}$ & $-0.002113^{*}$ & 0.009753 \\
Telecom & 0.042654 & 0.005955 & 0.01639 & $0.065269^{\wedge}$ \\
Utilities & -0.002547 & $-0.000697^{\wedge}$ & $-0.002313^{\wedge}$ & $0.011075^{* *}$ \\
\hline
\end{tabular}

${ }^{\wedge}$ significant at the $10 \%, *$ at the $5 \%$ and $* *$ at the $1 \%$ levels.

Table 3 (Continued) 
Panel C: Average estimated economic risk premiums for the size-BM portfolios

Panel C.1: Overall

\begin{tabular}{lcccc}
\hline Risk premia & Market & Inflation & Currency & Total \\
\hline LL & -0.012478 & -0.004346 & -0.009059 & -0.013725 \\
LM & $-0.002784^{*}$ & -0.001662 & -0.000365 & $0.005029^{\wedge}$ \\
LH & 0.246776 & -0.000497 & 0.0000499 & 0.264927 \\
ML & $-0.011346^{* *}$ & 0.001404 & -0.004369 & 0.014879 \\
MM & 0.015275 & 0.000496 & 0.001671 & $0.031532^{\wedge}$ \\
MH & $-0.101013^{* *}$ & 0.00802 & -0.001948 & $-0.08378^{* *}$ \\
HL & $-0.036892^{* *}$ & 0.003305 & -0.002409 & $-0.019355^{\wedge}$ \\
HM & $-0.030455^{* *}$ & 0.003754 & 0.000105 & -0.009685 \\
HH & 0.057574 & 0.000923 & 0.000275 & 0.077644 \\
\hline
\end{tabular}

Panel C.2: Pre-euro Period

\begin{tabular}{lcccc}
\hline Risk premia & Market & Inflation & Currency & Total \\
\hline LL & 0.004933 & 0.003094 & -0.037882 & -0.013779 \\
LM & $-0.006031^{\wedge}$ & -0.007161 & -0.001867 & 0.005981 \\
LH & 0.49803 & -0.001758 & -0.000241 & 0.528764 \\
ML & $-0.023014^{* *}$ & 0.000864 & -0.009673 & 0.027168 \\
MM & 0.04065 & -0.001286 & 0.003453 & $0.071369^{\wedge}$ \\
MH & $-0.200982^{* *}$ & 0.015206 & -0.004588 & $-0.17272^{* *}$ \\
HL & $-0.072897^{* *}$ & 0.004736 & -0.004966 & $-0.044585^{*}$ \\
HM & $-0.060278^{* *}$ & 0.005708 & -0.000319 & $-0.025755^{*}$ \\
HH & 0.116951 & 0.000473 & 0.0000348 & 0.150713 \\
\hline Panel C.3: Post-euro Period & & & & \\
\hline Risk premia & & & & \\
\hline LL & Market & Inflation & Currency & Total \\
LM & $-0.01804^{\wedge}$ & -0.006723 & 0.000149 & -0.013708 \\
LH & $-0.00134^{*}$ & 0.000781 & 0.000303 & $0.004606^{*}$ \\
ML & $-0.000988^{* *}$ & 0.000747 & 0.000337 & $0.004754^{* *}$ \\
MM & $-0.001784^{* *}$ & 0.001846 & -0.0000219 & $0.004809^{*}$ \\
MH & $-0.00129^{* *}$ & 0.00166 & 0.000508 & $0.005527^{* *}$ \\
HL & $-0.001044^{* *}$ & 0.000835 & $0.000692^{\wedge}$ & $0.00516^{* *}$ \\
HM & $-0.000887^{* *}$ & 0.001875 & 0.000149 & $0.005875^{* *}$ \\
HH & $-0.000632^{* *}$ & 0.0018 & 0.000528 & $0.006384^{* *}$ \\
\hline & $-0.000979^{* *}$ & 0.001367 & $0.000511^{\wedge}$ & $0.00559^{* *}$ \\
\hline
\end{tabular}

$\wedge$ significant at the $10 \%, *$ at the $5 \%$ and $* *$ at the $1 \%$ levels.

Table 3 (Continued) 
Panel A: Average exposures to the averaged beta risks

\begin{tabular}{|c|c|c|c|c|c|c|c|}
\hline & & $\beta^{\mathrm{m}}$ & $\beta^{d}$ & $\beta^{\mathrm{i}}$ & $\beta^{\mathrm{D}}$ & $\beta^{\lambda}$ & $\beta^{\mathrm{e}}$ \\
\hline \multirow{3}{*}{ Country portfolios } & Overall & $0.972967 * *$ & $0.729109 * *$ & -0.481408 & 0.027228 & 0.293639 & 57.0183 \\
\hline & Pre-euro Period & $1.199279 * *$ & 0.423322 & -0.942911 & 0.118221 & 0.112183 & 57.0183 \\
\hline & Post-euro Period & $0.746656^{* *}$ & $1.034896 * *$ & $-0.019904 *$ & $-0.063764^{\wedge}$ & $0.475095 * *$ & \\
\hline \multirow{3}{*}{ Sector portfolios } & Overall & $0.813539^{* *}$ & 5.462497 & -0.284535 & 0.110018 & 0.061189 & 25.59421 \\
\hline & Pre-euro Period & $0.928465 * *$ & 9.948686 & -0.538752 & 0.177178 & -0.440556 & 25.59421 \\
\hline & Post-euro Period & $0.698612 * *$ & $0.976309 * *$ & -0.030318 & 0.042858 & $0.562935 * *$ & \\
\hline \multirow{3}{*}{ Size-BM portfolios } & Overall & $1.18891 * *$ & 4.342045 & -0.659091 & 0.106149 & -0.077717 & $101.7787^{*}$ \\
\hline & Pre-euro Period & $1.730741^{* *}$ & 7.844354 & -1.290495 & -0.024311 & -0.525087 & $101.7787^{*}$ \\
\hline & Post-euro Period & $0.647078 * *$ & $0.839735 * *$ & $-0.027687 * *$ & 0.236609 & $0.369653 * *$ & \\
\hline
\end{tabular}

Panel B: Average estimated prices of risk from the AD-V model

\begin{tabular}{|c|c|c|c|c|c|c|}
\hline & & $\gamma^{\mathrm{m}}$ & $\gamma^{\mathrm{i}}$ & $\gamma^{\mathrm{D}}$ & $\gamma^{\lambda}$ & $\gamma^{\mathrm{e}}$ \\
\hline \multirow{3}{*}{ Country portfolios } & Overall & $0.004921 *$ & 0.073787 & $-0.006977^{\wedge}$ & $0.004023 *$ & 0.00000242 \\
\hline & Pre-euro Period & $0.001514 * *$ & $-0.001348 * *$ & -0.001519 & $0.00053 * *$ & 0.00000242 \\
\hline & Post-euro Period & $0.008328^{\wedge}$ & 0.148922 & $-0.012434^{\wedge}$ & $0.007517 *$ & \\
\hline \multirow{3}{*}{ Sector portfolios } & Overall & $0.027664^{\wedge}$ & $-0.238119^{\wedge}$ & $-0.07162 *$ & 0.001046 & $0.00000823^{* *}$ \\
\hline & Pre-euro Period & 0.000116 & $0.000166^{*}$ & 0.000337 & $0.000306^{* *}$ & $0.00000823 * *$ \\
\hline & Post-euro Period & $0.055211 *$ & $-0.476404 *$ & $-0.143578^{*}$ & 0.001785 & \\
\hline \multirow{3}{*}{ Size-BM portfolios } & Overall & -0.001308 & -0.222891 & -0.03924 & 0.002755 & $0.00000583 *$ \\
\hline & Pre-euro Period & -0.00017 & -0.000246 & -0.000338 & $0.000245 * *$ & $0.00000583 *$ \\
\hline & Post-euro Period & -0.002446 & -0.445536 & -0.078141 & 0.005265 & \\
\hline
\end{tabular}

Panel C: Forecast error variance decomposition of the common exchange risk premium from the AD-V Model (Cholesky decomposition order: market, exchange rate and inflation risk premium)

\begin{tabular}{|c|c|c|c|c|c|c|c|}
\hline \multicolumn{2}{|c|}{ 6-month-ahead } & SD & $\gamma^{\mathrm{m}}$ & $\gamma^{\mathrm{i}}$ & $\gamma^{\mathrm{D}}$ & $\gamma^{\lambda}$ & $\gamma^{\mathrm{e}}$ \\
\hline \multirow{2}{*}{$\begin{array}{l}\text { Country } \\
\text { Portfolios }\end{array}$} & Pre-euro Period & 0.000975 & 9.41 & 6.85 & 8.05 & 63.64 & 12.05 \\
\hline & Post-euro Period & 0.014542 & 3.08 & 5.90 & 0.06 & 90.96 & \\
\hline \multirow{2}{*}{$\begin{array}{l}\text { Sector } \\
\text { Portfolios }\end{array}$} & Pre-euro Period & 0.000674 & 18.95 & 3.11 & 2.75 & 73.62 & 1.56 \\
\hline & Post-euro Period & 0.066944 & 7.21 & 17.69 & 0.51 & 74.60 & \\
\hline \multirow{2}{*}{$\begin{array}{l}\text { Size-Book } \\
\text { Portfolios } \\
\end{array}$} & Pre-euro Period & 0.000979 & 4.24 & 3.54 & 5.32 & 86.51 & 0.38 \\
\hline & Post-euro Period & 0.019987 & 4.04 & 0.97 & 9.77 & 85.22 & \\
\hline \multicolumn{2}{|c|}{ 24-month-ahead } & SD & $\gamma^{\mathrm{m}}$ & $\gamma^{\mathrm{i}}$ & $\gamma^{\mathrm{D}}$ & $\gamma^{\lambda}$ & $\gamma^{\mathrm{e}}$ \\
\hline \multirow{2}{*}{$\begin{array}{l}\text { Country } \\
\text { Portfolios }\end{array}$} & Pre-euro Period & 0.000987 & 9.34 & 7.03 & 8.09 & 63.00 & 12.54 \\
\hline & Post-euro Period & 0.015231 & 3.01 & 10.15 & 0.19 & 86.65 & \\
\hline \multirow{2}{*}{$\begin{array}{l}\text { Sector } \\
\text { Portfolios }\end{array}$} & Pre-euro Period & 0.000683 & 20.93 & 4.70 & 3.41 & 69.15 & 1.81 \\
\hline & Post-euro Period & 0.072235 & 7.89 & 19.00 & 0.49 & 72.61 & \\
\hline \multirow{2}{*}{$\begin{array}{l}\text { Size-Book } \\
\text { Portfolios }\end{array}$} & Pre-euro Period & 0.000979 & 4.24 & 3.57 & 5.73 & 86.06 & 0.40 \\
\hline & Post-euro Period & 0.021316 & 6.63 & 2.53 & 9.82 & 81.02 & \\
\hline
\end{tabular}

${ }^{\wedge}$ significant at the $10 \%, *$ at the $5 \%$ and $* *$ at the $1 \%$ levels.

Table 4: Structural changes of the average of beta risks, and structural changes of risk premiums and forecast decomposition of the common exchange rate risk premium from the AD-V model 
Panel A: Specification tests from the augmented nationalized AD-V model

\begin{tabular}{|c|c|c|}
\hline $\mathrm{H}_{0}$ & Pre-euro & Post-euro \\
\hline $\begin{array}{l}\gamma_{0}^{\text {Austria }}=\gamma_{0}{ }^{\text {Belgium }}=\ldots=\gamma_{0}{ }^{\mathrm{UK}}=\gamma^{\mathrm{m}}=\ldots=\gamma^{\mathrm{e}}=\gamma^{\mathrm{m} \cdot \mathrm{div}} \\
=\ldots=\gamma^{\mathrm{e} \text { div }}=\gamma^{\mathrm{m} \cdot \mathrm{term}}=\ldots=\gamma^{\mathrm{e} \text { term }}=\gamma^{\text {div }}=\gamma^{\text {term }}=0\end{array}$ & $7597.869^{* *}$ & $102.8875^{* *}$ \\
\hline$\gamma_{0}^{\text {Austria }}=\gamma_{0}^{\text {Belgium }}=\ldots=\gamma_{0}{ }^{\mathrm{UK}}=\gamma^{\mathrm{d}}=\gamma^{\mathrm{d} \cdot \mathrm{div}}=\gamma^{\mathrm{d} \cdot \operatorname{term}}=0$ & $7597.066 * *$ & $22.857^{\wedge}$ \\
\hline$\gamma_{0}{ }^{\text {Austria }}=\gamma_{0}^{\text {Belgium }}=\ldots=\gamma_{0}{ }^{\mathrm{UK}}=0$ & $7485.05^{* *}$ & $20.02335^{\wedge}$ \\
\hline$\gamma_{0}^{\text {Austria }}=\gamma_{0}{ }^{\text {Belgium }}=\ldots=\gamma_{0}{ }^{\mathrm{UK}}$ & $3685.314^{* *}$ & $19.85155^{*}$ \\
\hline$\gamma^{\mathrm{d}}=\gamma^{\mathrm{d} \cdot \mathrm{div}}=\gamma^{\mathrm{d} \cdot \operatorname{term}}=0$ & $112.0162 * *$ & 2.833649 \\
\hline
\end{tabular}

Panel B: Average estimated specific country risks from the augmented nationalized AD-V model

\begin{tabular}{|c|c|c|c|c|c|c|c|}
\hline & Average & $\gamma_{0}{ }^{\text {Austria }}$ & $\gamma_{0}{ }^{\text {Belgium }}$ & $\gamma_{0}{ }^{\text {Finland }}$ & $\gamma_{0}{ }^{\text {France }}$ & $\gamma_{0}$ Germany & $\gamma_{0}{ }^{\text {Greece }}$ \\
\hline Overall & $0.038246^{* *}$ & $-0.012355^{* *}$ & 0.000506 & $0.101001^{* *}$ & $0.041207^{* *}$ & $0.043859^{* *}$ & $-0.022621^{* *}$ \\
\hline Pre-Amsterdam Treaty & $0.097163^{* *}$ & $-0.016592 * *$ & -0.000502 & $0.254072 * *$ & $0.091184 * *$ & $0.108793 * *$ & \\
\hline Post-Amsterdam Treaty & $0.003932^{\wedge}$ & $-0.009888^{* *}$ & 0.00055 & $0.01185^{*}$ & $0.0121 * *$ & 0.00604 & $-0.022621 * *$ \\
\hline Pre-euro Period & $0.075479 * *$ & $-0.016469 * *$ & 0.000867 & $0.199706^{* *}$ & $0.072766 * *$ & $0.087297 * *$ & \\
\hline \multirow[t]{2}{*}{ Post-euro Period } & 0.001013 & $-0.008242 * *$ & 0.00039 & 0.002296 & $0.009649 * *$ & 0.000421 & $-0.022621 * *$ \\
\hline & & $\gamma_{0}^{\text {Ireland }}$ & $\gamma_{0}{ }^{\text {Italy }}$ & $\gamma_{0}{ }^{\text {Netherlands }}$ & $\gamma_{0}{ }^{\text {Portugal }}$ & $\gamma_{0}$ Spain & $\gamma_{0}{ }^{\mathrm{UK}}$ \\
\hline Overall & & 0.00016 & $0.005924 * *$ & $0.030437 * *$ & -0.002162 & $0.002143^{\wedge}$ & $0.036928 * *$ \\
\hline Pre-Amsterdam Treaty & & & & $0.080728 * *$ & $-0.000574 *$ & $0.003694 * *$ & $0.06787 * *$ \\
\hline Post-Amsterdam Treaty & & 0.00016 & $0.005924 * *$ & 0.001146 & -0.002232 & 0.002075 & $0.018907 * *$ \\
\hline Pre-euro Period & & & $0.007915^{* *}$ & $0.064566^{* *}$ & $0.00499 * *$ & $0.004669^{* *}$ & $0.057682 * *$ \\
\hline Post-euro Period & & 0.00016 & $0.005426 * *$ & -0.003693 & $-0.004447^{\wedge}$ & 0.001336 & $0.016175 * *$ \\
\hline
\end{tabular}

^ significant at the $10 \%, *$ at the $5 \%$ and $* *$ at the $1 \%$ levels.

\section{Table 5: Selected specifications test from the augmented nationalized AD-V model and structural changes in the average of specific country risks}


Panel A: Specification tests from the nationalized AD-V model

\begin{tabular}{|c|c|c|c|c|c|c|}
\hline \multirow{2}{*}{$\mathrm{H}_{0}$} & \multicolumn{2}{|c|}{ Country portfolios } & \multicolumn{2}{|c|}{ Sector portfolios } & \multicolumn{2}{|c|}{ Size-BM portfolios } \\
\hline & Pre-euro & Post-euro & Pre-euro & Post-euro & Pre-euro & Post-euro \\
\hline $\begin{array}{l}\gamma_{0}=\gamma^{\mathrm{m}}=\ldots=\gamma^{\mathrm{e}}=\gamma^{\mathrm{m} \cdot \mathrm{div}}=\ldots=\gamma^{\mathrm{e} \text { div }} \\
=\gamma^{\mathrm{m} \cdot \mathrm{term}}=\ldots=\gamma^{\mathrm{e} \text { term }}=\gamma^{\text {div }}=\gamma^{\text {term }}=0\end{array}$ & $22313 * *$ & $1064.908 * *$ & $4591.463 * *$ & $2278.507^{* *}$ & $14567.18^{* *}$ & $295.2447 * *$ \\
\hline$\gamma^{\mathrm{m}}=\gamma^{\mathrm{m} \cdot \mathrm{div}}=\gamma^{\mathrm{m} \cdot \mathrm{term}}=0$ & $234.0274 * *$ & $49.04606 * *$ & $187.7534 * *$ & $93.53641 * *$ & $169.8319 * *$ & $45.70733 * *$ \\
\hline$\gamma^{\mathrm{d}}=\gamma^{\mathrm{d} \cdot \mathrm{div}}=\gamma^{\mathrm{d} \cdot \mathrm{term}}=0$ & $169.9015 * *$ & $9.596471^{*}$ & $113.6443 * *$ & $57.76337 * *$ & $155.9682 * *$ & $18.11493 * *$ \\
\hline $\begin{array}{l}\gamma^{\mathrm{i}}=\gamma^{\mathrm{i} \cdot \mathrm{div}}=\gamma^{\mathrm{i} \cdot \mathrm{term}}=\gamma^{\mathrm{D}}=\gamma^{\mathrm{D} \cdot \mathrm{div}}= \\
\gamma^{\mathrm{D} \cdot \mathrm{term}}=0\end{array}$ & $618.2298 * *$ & $21.53649 * *$ & $617.5981 * *$ & $31.28418^{* *}$ & $869.4452 * *$ & $25.26438^{* *}$ \\
\hline$\gamma^{\mathrm{i}}=\gamma^{\mathrm{i} \cdot \mathrm{div}}=\gamma^{\mathrm{i} \cdot \mathrm{term}}=0$ & $68.65894 * *$ & $11.81454 * *$ & $120.3392 * *$ & $25.4615 * *$ & $372.1269 * *$ & $22.4513^{* *}$ \\
\hline $\begin{array}{l}\gamma^{\mathrm{D}}=\gamma^{\mathrm{D} \cdot \mathrm{div}}=\gamma^{\mathrm{D} \cdot \mathrm{term}}=0 \\
\gamma^{\lambda}=\gamma^{\lambda \cdot \operatorname{div}}=\gamma^{\lambda \cdot \text { term }}=\gamma^{\mathrm{e}}=\gamma^{\mathrm{e} \cdot \operatorname{div}}=\end{array}$ & $131.6995 * *$ & 3.907576 & $44.28164 * *$ & $20.21041 * *$ & $339.0196 * *$ & $16.16854 * *$ \\
\hline $\begin{array}{l}\gamma^{\text {e.term }}=0 \text { (pre-euro) } / \\
\gamma^{\lambda}=\gamma^{\lambda \cdot \operatorname{div}}=\gamma^{\lambda \cdot \text { term }}=0 \text { (post-euro) }\end{array}$ & $512.1341 * *$ & $11.99617^{* *}$ & $386.6882 * *$ & $28.64508 * *$ & $386.7253 * *$ & $38.368 * *$ \\
\hline$\gamma^{\lambda}=\gamma^{\lambda \cdot \operatorname{div}}=\gamma^{\lambda \cdot \text { term }}=0$ & $141.1931 * *$ & $11.99617 * *$ & $114.5375 * *$ & $28.64508 * *$ & $202.0525 * *$ & $38.368 * *$ \\
\hline$\gamma^{\mathrm{e}}=\gamma^{\mathrm{e} \cdot \mathrm{div}}=\gamma^{\mathrm{e} \cdot \mathrm{term}}=0$ & $441.4134 * *$ & & $176.6507 * *$ & & $158.4525 * *$ & \\
\hline$\gamma^{\mathrm{div}}=\gamma^{\text {term }}=0$ & $55.40908^{* *}$ & $428.1211^{* *}$ & $168.8914 * *$ & $22.29958^{* *}$ & $70.41631^{* *}$ & $8.079383 *$ \\
\hline
\end{tabular}

Panel B: Average estimated prices of risk for the nationalized AD-V model

\begin{tabular}{|c|c|c|c|c|c|c|c|}
\hline & & $\gamma^{\mathrm{m}}$ & $\gamma^{\mathrm{d}}$ & $\gamma^{\mathrm{i}}$ & $\gamma^{\mathrm{D}}$ & $\gamma^{\lambda}$ & $\gamma^{\mathrm{e}}$ \\
\hline \multirow{3}{*}{ Country portfolios } & Overall & $0.005787^{*}$ & $-0.00734 *$ & 0.082271 & -0.003478 & 0.003871 & -0.00000242 \\
\hline & Pre-euro Period & 0.000104 & $-0.006013 * *$ & -0.000455 & $-0.001791^{\wedge}$ & $0.000115 * *$ & -0.00000242 \\
\hline & Post-euro Period & $0.01147 *$ & -0.008668 & 0.164997 & -0.005165 & $0.007628^{\wedge}$ & \\
\hline \multirow{3}{*}{ Sector portfolios } & Overall & $0.035943^{*}$ & $-0.020707 * *$ & $-0.41601^{\wedge}$ & $-0.11184^{\wedge}$ & 0.001063 & $0.00000111^{*}$ \\
\hline & Pre-euro Period & $0.001202 * *$ & $-0.018448 * *$ & 0.000117 & $-0.000464 * *$ & $0.0000528 * *$ & $0.00000111^{*}$ \\
\hline & Post-euro Period & $0.070685^{*}$ & $-0.022966^{\wedge}$ & $-0.832137^{*}$ & $-0.223216^{\wedge}$ & 0.002072 & \\
\hline \multirow{3}{*}{ Size-BM portfolios } & Overall & -0.003438 & $-0.01512 * *$ & -0.250147 & -0.043449 & 0.001798 & $-0.00000659 * *$ \\
\hline & Pre-euro Period & $0.000538 * *$ & $-0.028219 * *$ & -0.000203 & $-0.00108 * *$ & -0.000000637 & $-0.00000659 * *$ \\
\hline & Post-euro Period & $-0.007413^{\wedge}$ & -0.00202 & -0.500091 & -0.085818 & 0.003597 & \\
\hline
\end{tabular}

Panel C: Forecast error variance decomposition of the common exchange risk premium from the nationalized AD-V Model (Cholesky decomposition order: market, exchange rate, inflation and domestic risk premium)

\begin{tabular}{|c|c|c|c|c|c|c|c|c|}
\hline \multicolumn{2}{|c|}{ 6-month-ahead } & SD & $\gamma^{\mathrm{m}}$ & $\gamma^{\mathrm{d}}$ & $\gamma^{\mathrm{i}}$ & $\gamma^{\mathrm{D}}$ & $\gamma^{\lambda}$ & $\gamma^{\mathrm{e}}$ \\
\hline \multirow{2}{*}{$\begin{array}{l}\text { Country } \\
\text { Portfolios }\end{array}$} & Pre-euro Period & 0.011348 & 0.08 & 7.35 & 5.81 & 1.88 & 62.27 & 22.62 \\
\hline & Post-euro Period & 0.019427 & 3.02 & 0.41 & 15.20 & 5.79 & 75.58 & \\
\hline \multirow{2}{*}{$\begin{array}{l}\text { Sector } \\
\text { Portfolios }\end{array}$} & Pre-euro Period & 0.011323 & 32.40 & 0.79 & 0.51 & 1.53 & 58.94 & 5.83 \\
\hline & Post-euro Period & 0.038106 & 10.77 & 5.20 & 2.22 & 6.91 & 74.90 & \\
\hline \multirow{2}{*}{$\begin{array}{l}\text { Size-Book } \\
\text { Portfolios }\end{array}$} & Pre-euro Period & 0.012873 & 4.75 & 1.06 & 0.23 & 0.73 & 91.44 & 1.80 \\
\hline & Post-euro Period & 0.010213 & 1.47 & 0.28 & 11.35 & 3.04 & 83.85 & \\
\hline \multicolumn{2}{|c|}{ 24-month-ahead } & SD & $\gamma^{\mathrm{m}}$ & $\gamma^{\mathrm{d}}$ & $\gamma^{\mathrm{i}}$ & $\gamma^{\mathrm{D}}$ & $\gamma^{\lambda}$ & $\gamma^{\mathrm{e}}$ \\
\hline \multirow{2}{*}{$\begin{array}{l}\text { Country } \\
\text { Portfolios }\end{array}$} & Pre-euro Period & 0.01135 & 0.10 & 7.31 & 5.95 & 3.24 & 60.99 & 22.41 \\
\hline & Post-euro Period & 0.019724 & 3.33 & 0.52 & 22.81 & 5.35 & 67.99 & \\
\hline \multirow{2}{*}{$\begin{array}{l}\text { Sector } \\
\text { Portfolios }\end{array}$} & Pre-euro Period & 0.011675 & 29.43 & 0.73 & 0.57 & 2.17 & 61.80 & 5.30 \\
\hline & Post-euro Period & 0.041696 & 10.52 & 5.32 & 3.79 & 6.91 & 73.47 & \\
\hline \multirow{2}{*}{$\begin{array}{l}\text { Size-Book } \\
\text { Portfolios }\end{array}$} & Pre-euro Period & 0.013017 & 4.88 & 1.25 & 0.48 & 0.82 & 90.44 & 2.13 \\
\hline & Post-euro Period & 0.010874 & 2.40 & 0.67 & 20.84 & 3.14 & 72.95 & \\
\hline
\end{tabular}

^ significant at the $10 \%, *$ at the $5 \%$ and $* *$ at the $1 \%$ levels.

Table 6: Specifications test, structural changes of risk premiums and forecast decomposition of the common exchange rate risk premium from the nationalized AD-V model 
Panel A: Average estimated economic risk premiums for the country portfolios

Panel A.1: Overall

\begin{tabular}{lccccc}
\hline Risk premia & Market & Domestic & Inflation & Currency & Total \\
\hline Austria & 0.000637 & -0.001512 & $0.000365^{\wedge}$ & -0.000876 & $0.0088^{* *}$ \\
Belgium & 0.007569 & -0.049376 & 0.000217 & 0.000179 & -0.031159 \\
Finland & $-0.00548^{*}$ & $-0.015662^{* *}$ & -0.001438 & 0.00061 & $-0.012428^{*}$ \\
France & -0.000741 & $-0.007759^{* *}$ & -0.000792 & 0.000782 & 0.001372 \\
Germany & -0.000728 & $-0.008334^{* *}$ & -0.000499 & 0.000831 & 0.001289 \\
Greece & 0.027158 & -0.007372 & 0.215726 & 0.006865 & 0.246643 \\
Ireland & -0.009218 & 0.017024 & 0.001486 & 0.027755 & 0.056768 \\
Italy & $0.004379^{*}$ & 0.002031 & 0.000529 & $0.001426^{\wedge}$ & $0.01764^{*}$ \\
The Netherlands & -0.000724 & $-0.006944^{* *}$ & -0.000642 & 0.000136 & 0.001738 \\
Portugal & 0.013872 & -0.052781 & 0.000246 & 0.00048 & -0.026966 \\
Spain & 0.016012 & -0.083291 & 0.000266 & 0.0000727 & -0.056554 \\
The United Kingdom & -0.000512 & $-0.005285^{* *}$ & 0.000131 & 0.000257 & $0.004678^{*}$ \\
\hline
\end{tabular}

Panel A.2: Pre-euro Period

\begin{tabular}{|c|c|c|c|c|c|}
\hline Risk premia & Market & Domestic & Inflation & Currency & Total \\
\hline Austria & $-0.000748^{\wedge}$ & -0.002072 & $0.000832 *$ & -0.002204 & $0.014542 * *$ \\
\hline Belgium & 0.012313 & -0.097554 & 0.0000147 & 0.000162 & -0.066287 \\
\hline Finland & $-0.014331 * *$ & $-0.028134 * *$ & -0.003176 & 0.000933 & $-0.027507 * *$ \\
\hline France & $-0.004818^{* *}$ & $-0.013642 * *$ & -0.001397 & 0.000137 & -0.001599 \\
\hline Germany & $-0.006257 * *$ & $-0.01342 * *$ & -0.001225 & 0.000862 & -0.002051 \\
\hline Greece & $-0.004896^{* *}$ & -0.001576 & 0.003056 & 0.004957 & 0.000589 \\
\hline Ireland & $-0.001775^{\wedge}$ & -0.000946 & $-0.007475^{*}$ & 0.110314 & 0.099943 \\
\hline Italy & 0.004722 & 0.010191 & 0.0000664 & 0.002617 & $0.034674 *$ \\
\hline The Netherlands & $-0.004769 * *$ & $-0.011794 * *$ & -0.001098 & -0.0000617 & 0.0002 \\
\hline Portugal & 0.024023 & -0.100712 & 0.0000761 & 0.000353 & -0.055918 \\
\hline Spain & 0.029347 & -0.166135 & 0.000415 & -0.0000602 & -0.117406 \\
\hline The United Kingdom & $-0.003126^{* *}$ & $-0.008567^{*}$ & -0.000718 & 0.000422 & $0.006545^{\wedge}$ \\
\hline \multicolumn{6}{|c|}{ Panel A.3: Post-euro Period } \\
\hline Risk premia & Market & Domestic & Inflation & Currency & Total \\
\hline Austria & $0.002023^{*}$ & -0.000953 & -0.000103 & 0.000451 & $0.003058^{\wedge}$ \\
\hline Belgium & $0.002892 *$ & -0.001868 & 0.000417 & 0.000196 & $0.003481 *$ \\
\hline Finland & $0.003371^{*}$ & -0.003191 & 0.000299 & 0.000288 & $0.002652^{\wedge}$ \\
\hline France & $0.003336 * *$ & -0.001877 & -0.000186 & 0.001427 & $0.004343 *$ \\
\hline Germany & $0.0048 * *$ & -0.003248 & 0.000227 & 0.000801 & $0.004629 *$ \\
\hline Greece & 0.032056 & -0.008258 & 0.248217 & 0.007156 & 0.284235 \\
\hline Ireland & -0.011595 & 0.022764 & 0.004348 & 0.001382 & 0.042976 \\
\hline Italy & $0.004063 *$ & -0.005448 & 0.000953 & 0.000334 & 0.002025 \\
\hline The Netherlands & $0.003322 *$ & -0.002094 & -0.000187 & 0.000334 & $0.003277 *$ \\
\hline Portugal & $0.003861 *$ & -0.005515 & 0.000414 & 0.000605 & 0.001585 \\
\hline Spain & $0.002862 *$ & -0.001598 & 0.00012 & 0.000204 & $0.003452 *$ \\
\hline The United Kingdom & $0.002103 *$ & -0.002002 & $0.000979^{\wedge}$ & 0.0000932 & $0.002811^{\wedge}$ \\
\hline
\end{tabular}

^ significant at the $10 \%, *$ at the $5 \%$ and $* *$ at the $1 \%$ levels.

Table 7: Average estimated economic risks premiums from the nationalized AD-V model 
Panel B: Average estimated economic risk premiums for the sector portfolios

Panel B1: Overall

\begin{tabular}{lccccc}
\hline Risk premia & Market & Domestic & Inflation & Currency & Total \\
\hline Basic & $-0.002823^{*}$ & $-0.012013^{* *}$ & 0.003718 & -0.001539 & $0.007427^{* *}$ \\
Cyclical & $-0.002893^{*}$ & $-0.007984^{* *}$ & $0.004415^{\wedge}$ & $-0.001263^{\wedge}$ & $0.011685^{* *}$ \\
Energy & 0.006348 & -0.001258 & -0.001573 & $-0.003203^{\wedge}$ & 0.013958 \\
Financial & $-0.003703^{*}$ & $-0.031052^{* *}$ & 0.006094 & -0.000676 & -0.009276 \\
Health & 0.02324 & -0.050092 & $0.00448^{*}$ & $-0.001112^{\wedge}$ & -0.00386 \\
Industrial & -0.04125 & 0.057132 & $0.002181^{\wedge}$ & -0.0006 & 0.03794 \\
Non Cyclical & $-0.00242^{* *}$ & -0.530424 & $0.002051^{*}$ & -0.000801 & -0.497979 \\
Technology & -0.004495 & -4.38308 & $0.009192^{*}$ & -0.002555 & -4.345135 \\
Telecom & 0.034814 & -0.00413 & 0.001481 & 0.002333 & 0.031651 \\
Utilities & 0.027601 & $-0.19596^{\wedge}$ & 0.000357 & -0.001057 & -0.148654 \\
\hline
\end{tabular}

Panel B.2: Pre-euro Period

\begin{tabular}{lccccc}
\hline Risk premia & Market & Domestic & Inflation & Currency & Total \\
\hline Basic & $-0.001655^{*}$ & $-0.022269^{* *}$ & 0.002315 & -0.000238 & 0.004955 \\
Cyclical & $-0.00134^{*}$ & $-0.013547^{* *}$ & 0.002351 & -0.000916 & $0.012675^{* *}$ \\
Energy & -0.000751 & 0.00302 & -0.007805 & -0.005917 & 0.005822 \\
Financial & $-0.003826^{\wedge}$ & $-0.058836^{* *}$ & 0.005504 & 0.000893 & $-0.030026^{*}$ \\
Health & 0.051445 & -0.097748 & 0.000357 & $0.000322^{*}$ & -0.018958 \\
Industrial & -0.078449 & 0.117223 & -0.0000596 & $0.000544^{* *}$ & 0.0669 \\
Non Cyclical & $-0.001604^{\wedge}$ & -1.175786 & 0.000355 & 0.001465 & -1.118133 \\
Technology & $-0.00194^{*}$ & -9.724798 & 0.000636 & -0.00263 & -9.657616 \\
Telecom & 0.007317 & 0.013344 & -0.017687 & -0.029357 & -0.009061 \\
Utilities & 0.058083 & $-0.394197^{\wedge}$ & 0.000976 & 0.000242 & -0.308526 \\
\hline Panel B.3: Post-euro Period & & & & & \\
\hline Risk premia & & & & & Currency \\
\hline Basic & Market & Domestic & Inflation & Total \\
Cyclical & $-0.00399^{\wedge}$ & -0.001756 & $0.00512^{*}$ & $-0.002839^{*}$ & $0.009899^{* *}$ \\
Energy & -0.004445 & $-0.002422^{\wedge}$ & $0.006478^{*}$ & $-0.001611^{*}$ & $0.010694^{* *}$ \\
Financial & 0.009799 & -0.003337 & 0.001457 & -0.001883 & 0.017913 \\
Health & $-0.00358^{\wedge}$ & $-0.003269^{*}$ & $0.006684^{*}$ & $-0.002245^{*}$ & $0.011473^{* *}$ \\
Industrial & -0.004573 & $-0.003097^{*}$ & $0.008545^{*}$ & $-0.002526^{*}$ & $0.011029^{*}$ \\
Non Cyclical & $-0.004568^{\wedge}$ & -0.002126 & $0.00439^{*}$ & $-0.001729^{*}$ & $0.009382^{* *}$ \\
Technology & $-0.003089^{*}$ & -0.001587 & $0.003441^{*}$ & $-0.002657^{*}$ & $0.010202^{* *}$ \\
Telecom & -0.006589 & $-0.005839^{\wedge}$ & $0.016203^{*}$ & $-0.002494^{*}$ & 0.008148 \\
Utilities & 0.04818 & -0.012624 & 0.010799 & 0.017738 & 0.051442 \\
\hline & $-0.002457^{*}$ & -0.000476 & $-0.000254^{\wedge}$ & $-0.002338^{\wedge}$ & $0.008998^{* *}$ \\
\hline
\end{tabular}

$\wedge$ significant at the $10 \%, *$ at the $5 \%$ and $* *$ at the $1 \%$ levels.

Table 7 (Continued) 
Panel C: Average estimated economic risk premiums for the size-BM portfolios

Panel C.1: Overall

\begin{tabular}{lccccc}
\hline Risk premia & Market & Domestic & Inflation & Currency & Total \\
\hline LL & $-0.014974^{\wedge}$ & 0.008437 & -0.005071 & -0.008407 & -0.007129 \\
LM & $-0.002679^{*}$ & -0.019002 & 0.000304 & -0.000509 & -0.014375 \\
LH & 0.022908 & -0.183333 & -0.000477 & 0.000755 & -0.151381 \\
ML & $-0.003035^{* *}$ & -1.823675 & -0.000368 & -0.002564 & -1.799196 \\
MM & -0.001001 & -0.025437 & 0.000144 & 0.001646 & -0.016598 \\
MH & $-0.00655^{\wedge}$ & $-0.11662^{* *}$ & 0.007043 & -0.003563 & $-0.102029^{* *}$ \\
HL & $-0.00318^{* *}$ & $-0.043999^{* *}$ & 0.003132 & -0.002188 & $-0.034095^{* *}$ \\
HM & $-0.002309^{*}$ & $-0.035863^{* *}$ & 0.003341 & -0.000568 & $-0.024044^{* *}$ \\
HH & 0.004915 & -0.126171 & 0.000768 & $0.000533^{\wedge}$ & -0.111596 \\
\hline
\end{tabular}

Panel C.2: Pre-euro Period

\begin{tabular}{lccccc}
\hline Risk premia & Market & Domestic & Inflation & Currency & Total \\
\hline LL & 0.005121 & 0.045259 & 0.001951 & -0.035528 & 0.033989 \\
LM & -0.002355 & -0.060892 & -0.000387 & -0.002457 & -0.053726 \\
LH & 0.048075 & -0.368928 & -0.001521 & 0.001069 & -0.308853 \\
ML & $-0.001986^{* *}$ & -4.048586 & -0.002706 & -0.005749 & -3.997809 \\
MM & 0.001649 & -0.064073 & -0.001799 & 0.003205 & -0.04847 \\
MH & -0.011021 & $-0.233036^{* *}$ & 0.013461 & -0.007935 & $-0.208358^{* *}$ \\
HL & $-0.004507^{*}$ & $-0.086956^{* *}$ & 0.004538 & -0.004417 & $-0.072283^{* *}$ \\
HM & $-0.003313^{\wedge}$ & $-0.070778^{* *}$ & 0.005056 & -0.001617 & $-0.053117^{* *}$ \\
HH & 0.011894 & -0.253883 & 0.000521 & 0.000488 & -0.229372 \\
\hline Panel C.3: Post-euro Period & & & & & \\
\hline Risk premia & & & & & Currency \\
\hline LL & Market & Domestic & Inflation & Total \\
LM & $-0.021394^{\wedge}$ & -0.003326 & -0.007314 & 0.000257 & -0.020264 \\
LH & $-0.002823^{* *}$ & $-0.000384^{\wedge}$ & 0.000611 & 0.000357 & $0.003115^{\wedge}$ \\
ML & $-0.00191^{* *}$ & $-0.000316^{*}$ & 0.000553 & $0.000446^{\wedge}$ & $0.003903^{*}$ \\
MM & $-0.003895^{* *}$ & $-0.000484^{*}$ & 0.001548 & 0.0000462 & 0.002444 \\
MH & $-0.002731^{* *}$ & $-0.000217^{*}$ & 0.001412 & $0.000629^{\wedge}$ & $0.004207^{*}$ \\
HL & $-0.002079^{* *}$ & $-0.000204^{*}$ & 0.000626 & $0.000808^{*}$ & $0.004301^{*}$ \\
HM & $-0.001852^{* *}$ & $-0.001041^{\wedge}$ & 0.001726 & 0.0000409 & $0.004093^{*}$ \\
HH & $-0.001304^{* *}$ & $-0.000948^{\wedge}$ & 0.001625 & 0.00048 & $0.005028^{* *}$ \\
\hline
\end{tabular}

$\wedge$ significant at the $10 \%, *$ at the $5 \%$ and $* *$ at the $1 \%$ levels.

Table 7 (Continued) 


\begin{tabular}{|c|c|c|c|c|c|c|c|c|}
\hline \multicolumn{2}{|c|}{ 6-month-ahead } & SD & $\gamma^{\mathrm{m}}$ & $\gamma^{\mathrm{d}}$ & $\gamma^{\mathrm{i}}$ & $\gamma^{\mathrm{D}}$ & $\gamma^{\lambda}$ & $\gamma^{\mathrm{e}}$ \\
\hline \multirow{2}{*}{$\begin{array}{l}\text { Country } \\
\text { Portfolios }\end{array}$} & Pre-euro Period & 0.011348 & 21.36 & 78.19 & 0.03 & 0.21 & 0.02 & 0.19 \\
\hline & Post-euro Period & 0.019427 & 33.16 & 59.69 & 5.40 & 0.92 & 0.83 & \\
\hline \multirow{2}{*}{$\begin{array}{l}\text { Sector } \\
\text { Portfolios } \\
\end{array}$} & Pre-euro Period & 0.011323 & 14.88 & 63.59 & 0.15 & 2.55 & 18.54 & 0.28 \\
\hline & Post-euro Period & 0.038106 & 16.31 & 52.81 & 10.15 & 1.31 & 19.43 & \\
\hline \multirow{2}{*}{$\begin{array}{l}\text { Size-Book } \\
\text { Portfolios } \\
\end{array}$} & Pre-euro Period & 0.012873 & 3.01 & 80.39 & 4.43 & 1.27 & 8.29 & 2.61 \\
\hline & Post-euro Period & 0.010213 & 0.85 & 78.32 & 10.86 & 2.46 & 7.52 & \\
\hline \multicolumn{2}{|c|}{ 24-month-ahead } & SD & $\gamma^{\mathrm{m}}$ & $\gamma^{\mathrm{d}}$ & $\gamma^{\mathrm{i}}$ & $\gamma^{\mathrm{D}}$ & $\gamma^{\lambda}$ & $\gamma^{\mathrm{e}}$ \\
\hline \multirow{2}{*}{$\begin{array}{l}\text { Country } \\
\text { Portfolios } \\
\end{array}$} & Pre-euro Period & 0.01135 & 21.36 & 78.17 & 0.04 & 0.22 & 0.02 & 0.19 \\
\hline & Post-euro Period & 0.019724 & 32.58 & 57.95 & 5.97 & 1.02 & 2.48 & \\
\hline \multirow{2}{*}{$\begin{array}{l}\text { Sector } \\
\text { Portfolios } \\
\end{array}$} & Pre-euro Period & 0.011675 & 14.01 & 61.23 & 0.22 & 2.90 & 21.38 & 0.27 \\
\hline & Post-euro Period & 0.041696 & 14.04 & 46.74 & 13.85 & 2.77 & 22.60 & \\
\hline \multirow{2}{*}{$\begin{array}{l}\text { Size-Book } \\
\text { Portfolios } \\
\end{array}$} & Pre-euro Period & 0.013017 & 3.38 & 78.64 & 4.38 & 1.62 & 9.40 & 2.58 \\
\hline & Post-euro Period & 0.010874 & 1.92 & 71.18 & 12.58 & 2.49 & 11.84 & \\
\hline
\end{tabular}

Cholesky decomposition order: market, domestic, exchange rate and inflation risk premium.

Table 8: Forecast decomposition of the domestic risk premium from the nationalized AD-V model 


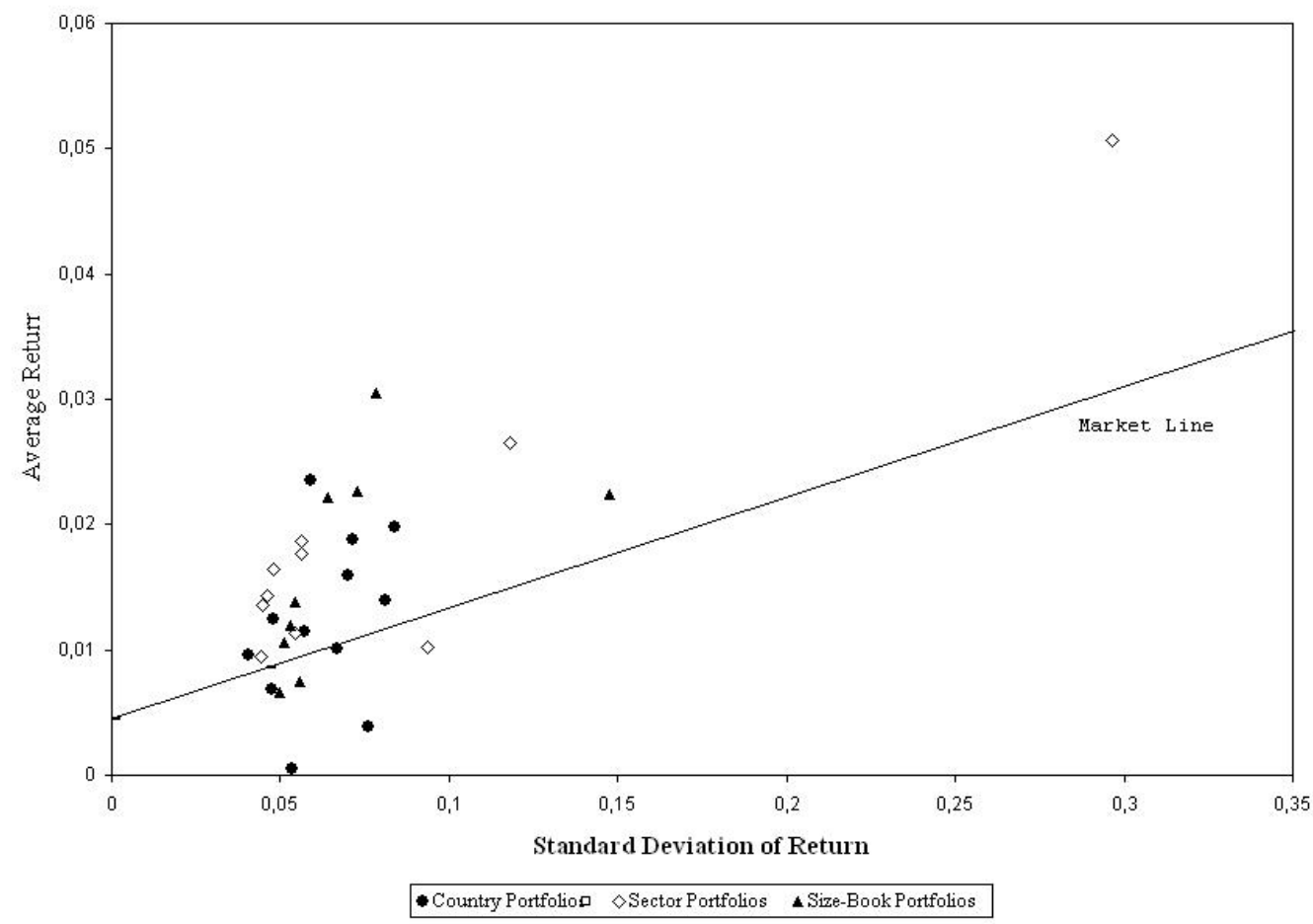

Figure 1: Country, sector and size-BM portfolios total returns 

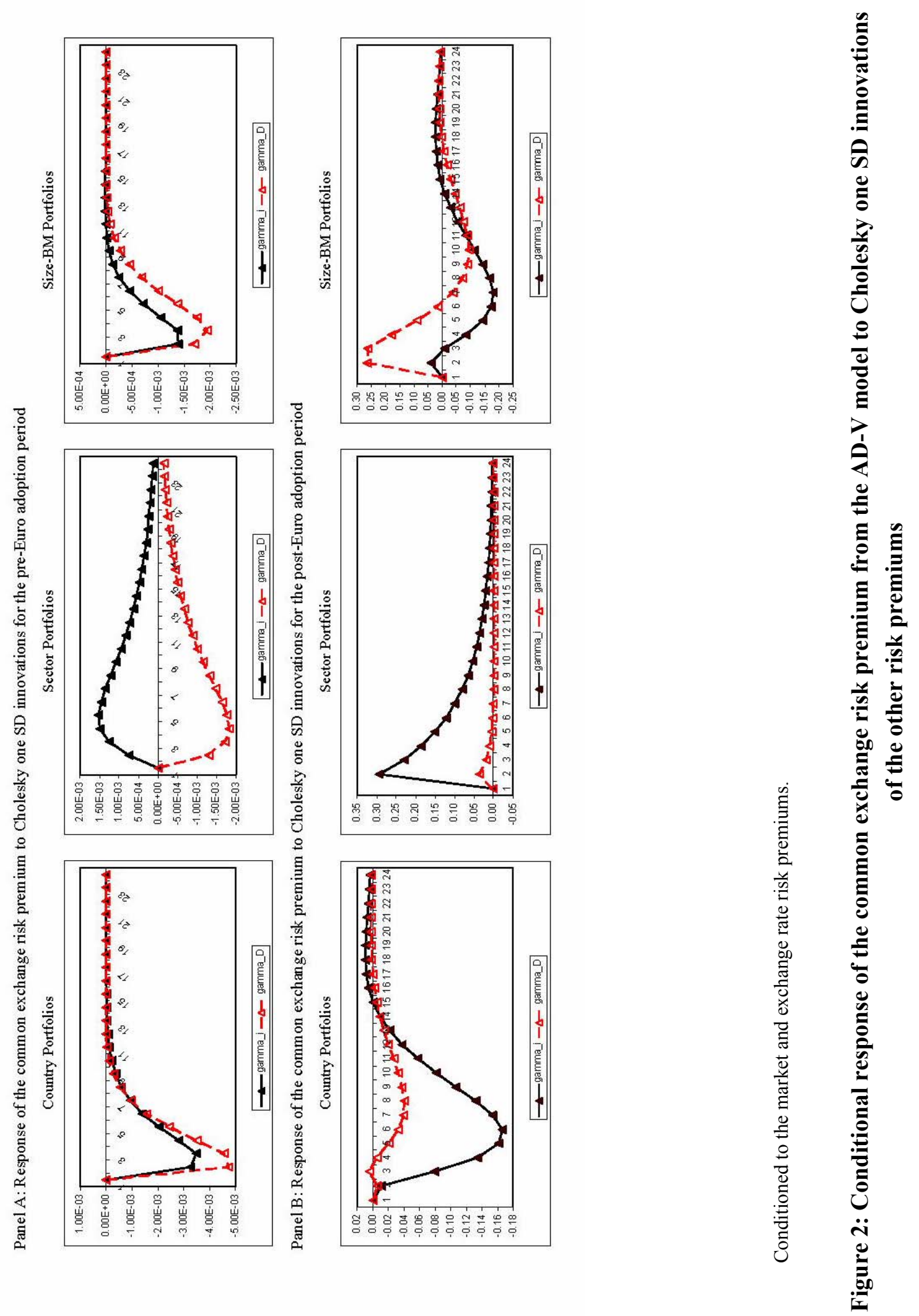

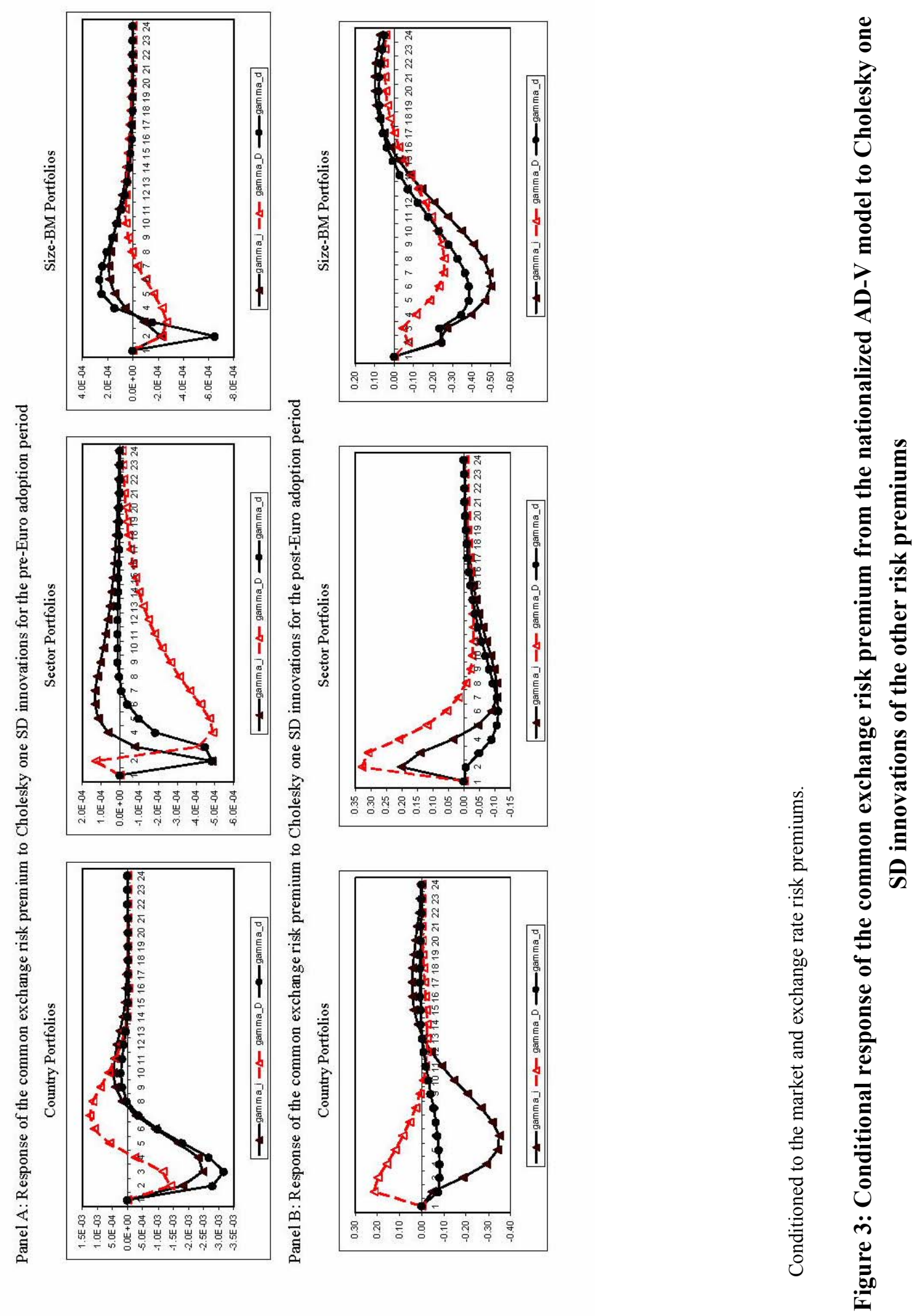

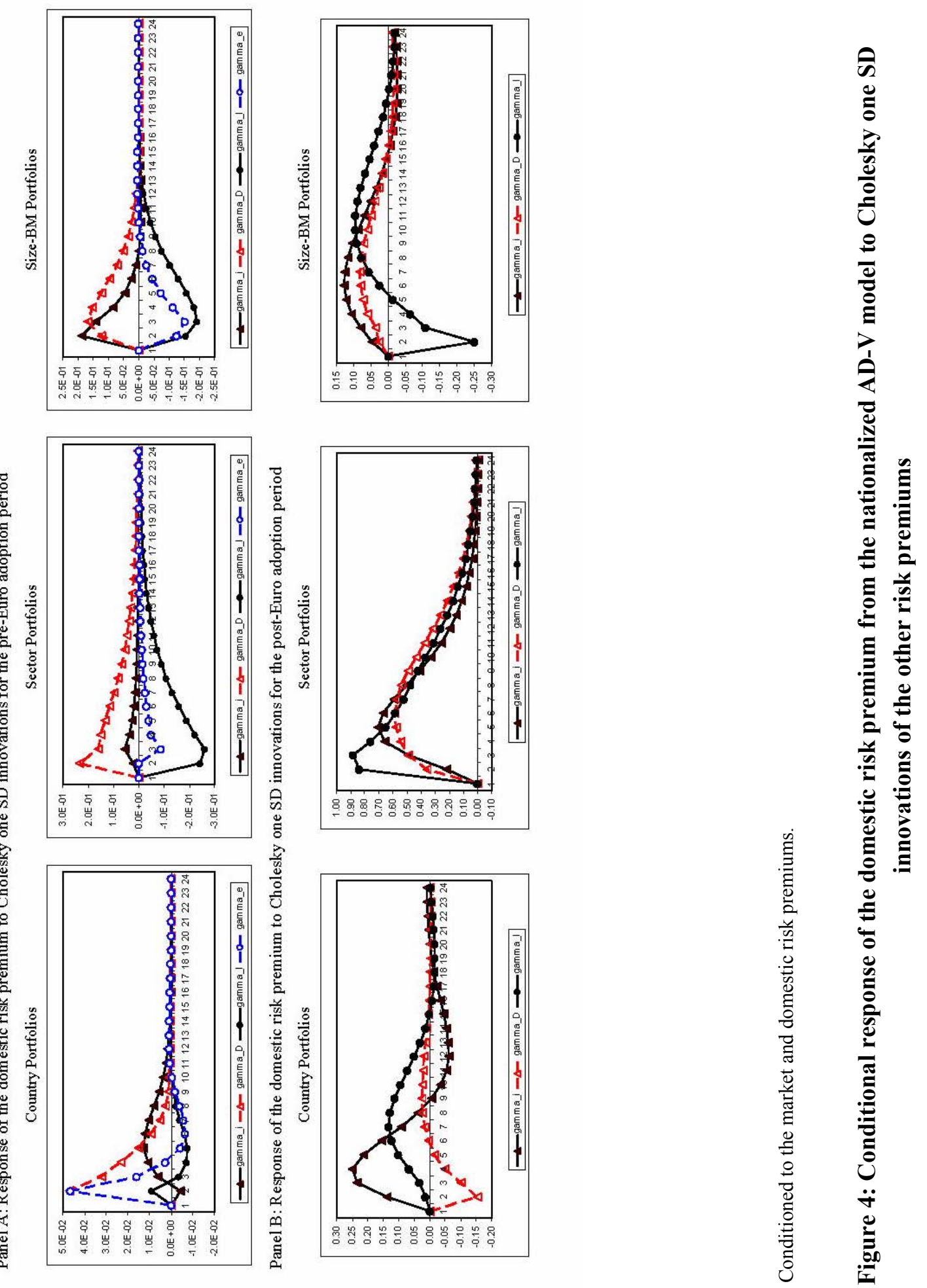